OPEN ACCESS

Edited by:

Xin Chen,

University of California, San Francisco,

United States

Reviewed by:

Yangfu Jiang,

Sichuan University, China

Zhaoming Li,

The First Affiliated Hospital of

Zhengzhou University, China

Wenmei Su,

Affiliated Hospital of Guangdong

Medical University, China

${ }^{*}$ Correspondence:

Kongju Wu

1005846823@qq.com

Kongming Wu

kmwu@tjh.tjmu.edu.cn

Specialty section:

This article was submitted to

Gastrointestinal Cancers,

a section of the journal

Frontiers in Oncology

Received: 03 June 2021

Accepted: 12 July 2021

Published: 26 July 2021

Citation:

Niu M, Yi M, Li N, Wu K and Wu K (2021) Advances of Targeted Therapy for Hepatocellular Carcinoma.

Front. Oncol. 11:719896. doi: 10.3389/fonc.2021.719896

\section{Advances of Targeted Therapy for Hepatocellular Carcinoma}

\author{
Mengke $\mathrm{Niu}^{1}$, Ming $\mathrm{Yi}^{1}{ }^{1}$, Ning $\mathrm{Li}^{2}$, Kongju $\mathrm{Wu}^{3 *}$ and Kongming $\mathrm{Wu}{ }^{1,2 *}$ \\ ${ }^{1}$ Department of Oncology, Tongji Hospital of Tongji Medical College, Huazhong University of Science and Technology, \\ Wuhan, China, 2 Department of Medical Oncology, The Affiliated Cancer Hospital of Zhengzhou University, Henan Cancer \\ Hospital, Zhengzhou, China, ${ }^{3}$ Department of Nursing, Medical School of Pingdingshan University, Pingdingshan, China
}

Hepatocellular carcinoma ( $\mathrm{HCC}$ ) is one of the common and fatal malignancies, which is a significant global health problem. The clinical applicability of traditional surgery and other locoregional therapies is limited, and these therapeutic strategies are far from satisfactory in improving the outcomes of advanced HCC. In the past decade, targeted therapy had made a ground-breaking progress in advanced HCC. Those targeted therapies exert antitumor effects through specific signals, including anti-angiogenesis or cell cycle progression. As a standard systemic therapy option, it tremendously improves the survival of this devastating disease. Moreover, the combination of targeted therapy with immune checkpoint inhibitor $(\mathrm{ICl})$ has demonstrated more potent anticancer effects and becomes the hot topic in clinical studies. The combining medications bring about a paradigm shift in the treatment of advanced HCC. In this review, we presented all approved targeted agents for advanced HCC with an emphasis on their clinical efficacy, summarized the advances of multi-target drugs in research for HCC and potential therapeutic targets for drug development. We also discussed the exciting results of the combination between targeted therapy and ICl.

Keywords: hepatocellular carcinoma, targeted therapy, tyrosine kinase inhibitors, immune checkpoint inhibitors, clinical trials

\section{INTRODUCTION}

Hepatocellular carcinoma (HCC) accounts for approximately $75 \%-85 \%$ of all primary liver cancer (1). Several risk factors such as chronic hepatitis B virus (HBV) and hepatitis C virus (HCV) infections, autoimmune hepatitis, alcohol abuse, diabetes, obesity induce liver injury and produce an inflammatory environment, which lead to hepatocyte necrosis, repeated regeneration and chromosomal instability $(2,3)$. The gradual accumulation of genetic and epigenetic abnormalities in this background plays an essential role in hepatocarcinogenesis (4). As curative treatments, surgical resection, radiofrequency ablation (RFA), transarterial chemoembolization (TACE) and liver transplant (LT) prolong the survival of HCC patients at early-or intermediate-stages (5-7). However, the high incidence of recurrence indicates poor survival prospects (8-11). Besides, most of HCCs are diagnosed at an advanced stage due to its insidious onset and rapid progression (7). Palliative treatments are therefore crucial in the management of advanced HCC. The efficacy of systemic chemotherapy for advanced HCC is disappointing (12). 
In recent years, molecular biology techniques are rapidly developing, such as whole exome sequencing, copy number analyses, mRNA-seq, miRNA-seq, methylomics and proteomics (13-15). Multiplex molecular profiling of HCC deepens on the understanding of aberrant molecular events and pivotal signaling pathways associated with the development of HCC, especially tyrosine kinase-related signaling (14). In general, tyrosine kinases can be classified as receptor tyrosine kinases (RTKs) and non-receptor tyrosine kinases (nRTKs) (16). RTKs transmit extracellular signals and nRTKs mediate intracellular communications (16). RTKs are receptors of a variety of subfamilies, including vascular endothelial growth factor receptor (VEGFR), platelet-derived growth factor receptor (PDGFR), epidermal growth factor receptor (EGFR), fibroblast growth factor receptor (FGFR), hepatocyte growth factor receptor (HGFR), Tie-2 and RET (Figure 1) (17-20). RTK consists of an extracellular domain that binds specific ligand, a transmembrane domain and an intracellular domain with tyrosine kinase activity (21). The binding of RTK to its ligand phosphorylates tyrosine residues of target protein and regulates a series of biochemical processes through corresponding downstream signaling pathways $(17,18)$.

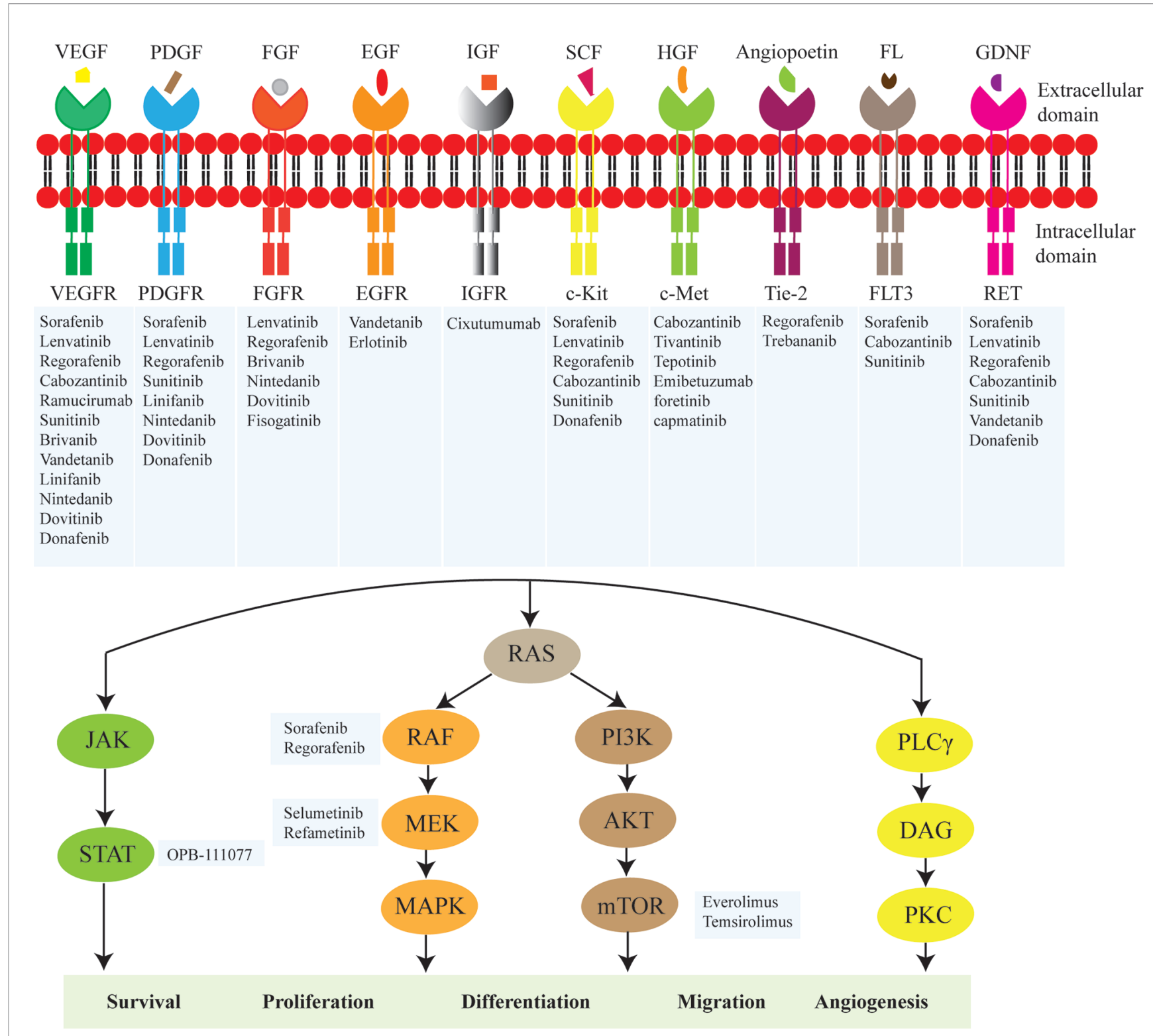

FIGURE 1 | Main molecules of targeted therapy for hepatocellular carcinoma (HCC). The major targets include vascular endothelial growth factor receptor (VEGFR), platelet-derived growth factor receptor (PDGFR), FGF receptor (FGFR), epidermal growth factor receptor (EGFR), insulin-like growth factor receptor (IGFR), c-Kit, hepatocyte growth factor receptor (c-Met), Tie-2, FLT3, RET, RAF, MEK, STAT, and mTOR. The key mechanisms are to inhibit the activity of tyrosine kinase in the intracellular domain of the receptor tyrosine kinase or directly block the transduction of downstream signals involved in cell survival, proliferation, differentiation, migration and angiogenesis. 
Functional mutations, genomic amplification, chromosomal rearrangements and/or autocrine activation lead to oncogenic activation of RTK, ultimately leading to carcinogenesis, invasion, metastasis, and angiogenesis $(17,22,23)$. The emergence of tyrosine kinase inhibitors (TKIs) has become a promising targeted therapeutic strategy $(24,25)$. TKIs can enter cells and interact with the intracellular domain of multiple receptors and other intracellular signaling molecules, blocking the phosphorylation of tyrosine residues and the activation of various downstream signaling pathways such as the Ras/Raf/ MEK/MAPK and PI3K/AKT/mTOR (16).

Given the current investigation, multiple drugs have been approved for advanced HCC (Table 1). The emergence of targeted therapy has transformed the therapeutic landscape of advanced HCC $(5,24,26-28)$. Despite advances in targeted therapy, overall response rate and 5-year survival rate remain unsatisfactory (29). The inevitable development of drug resistance and toxicity, and the absence of specific biomarkers to screen patients sensitive to these agents, have spurred the further exploration of novel therapeutic targets and strategies (29-31).

Effective combination therapy is needed due to the limited efficacy of monotherapy. Recent studies have shown that combinations of multiple therapeutic regimens demonstrated superior efficacy to monotherapy, particularly combination of targeted therapy with immune checkpoint inhibitor (ICI) (32). Notably, the approval of atezolizumab plus bevacizumab as the first-line setting for patients with unresectable or metastatic HCC alters the outlook for this disease. This review focused on the advances of targeted therapy for advanced HCC.

TABLE 1 | Principal clinical trials for the FDA-approval of targeted and immunotherapeutic drugs for HCC.

\begin{tabular}{|c|c|c|c|c|c|c|}
\hline Drugs & Main targets & $\begin{array}{l}\text { Treatment } \\
\text { line }\end{array}$ & Pivotal study & Study design & Results & $\begin{array}{l}\text { Approval } \\
\text { time }\end{array}$ \\
\hline Sorafenib & $\begin{array}{l}\text { VEGFRs, PDGFR- } \beta \text {, c-Kit, } \\
\text { FLT3, RET }\end{array}$ & First-line & NCT00105443 & $\begin{array}{l}\text { Phase III, sorafenib vs. } \\
\text { placebo }\end{array}$ & $\begin{array}{l}\text { OS: } 10.7 \text { vs. } 7.9 \text { months (HR } 0.69 ; 95 \% \\
\text { Cl: } 0.55-0.87, p<0.001) \\
\text { Time to radiologic progression: } 5.5 \text { vs. } 2.8 \text { months } \\
\text { (HR } 0.58 ; 95 \% \mathrm{Cl}: 0.45-0.74, p<0.001) \\
\text { ORR: } 2 \% \text { vs. } 1 \%\end{array}$ & 2007 \\
\hline Lenvatinib & $\begin{array}{l}\text { VEGFR1-3, FGFR1-4, } \\
\text { PDGFR- } \alpha, \text { RET, c-Kit }\end{array}$ & First-line & NCT01761266 & $\begin{array}{l}\text { Phase III, lenvatinib vs. } \\
\text { sorafenib }\end{array}$ & $\begin{array}{l}\text { OS: } 13.6 \text { vs. } 12.3 \text { months (HR 0.92; 95\% } \\
\text { Cl: } 0.79-1.06) \\
\text { PFS: } 7.4 \text { vs. } 3.7 \text { months (HR 0.66; } 95 \% \\
\text { Cl: } 0.57-0.77, p<0.0001) \\
\text { TTP: } 8.9 \text { vs. } 3.7 \text { months (HR } 0.63 ; 95 \% \\
\text { Cl: } 0.53-0.73, p<0.0001) \\
\text { ORR: } 40.6 \% \text { vs. } 12.4 \%\end{array}$ & 2018 \\
\hline $\begin{array}{l}\text { Atezolizumab } \\
\text { plus } \\
\text { Bevacizumab }\end{array}$ & PD-L1 VEGF & First-line & NCT03434379 & $\begin{array}{l}\text { Phase Ib, atezolizumab } \\
\text { plus bevacizumab vs. } \\
\text { sorafenib }\end{array}$ & $\begin{array}{l}\text { Survival rates at } 12 \text { months: } 67.2 \% \text { vs. } 54.6 \% \\
\text { PFS: } 6.8 \text { vs. } 4.3 \text { months (HR } 0.59 ; 95 \% \\
\text { Cl: } 0.47-0.76, p<0.001) \\
\text { ORR: } 33.2 \% \text { vs. } 13.3 \%\end{array}$ & 2020 \\
\hline Regorafenib & $\begin{array}{l}\text { VEGFR1-3, PDGFR- } \beta \text {, } \\
\text { FGFR1, Tie-2, c-Kit, RET, } \\
\text { B-RAF }\end{array}$ & Second-line & NCT01774344 & $\begin{array}{l}\text { Phase III, regorafenib vs. } \\
\text { placebo }\end{array}$ & $\begin{array}{l}\text { OS: } 10.6 \text { vs. } 7.8 \text { months (HR 0.63; } 95 \% \\
\text { Cl: } 0.50-0.79, p<0.0001) \\
\text { PFS: } 3.1 \text { vs. } 1.5 \text { months (HR } 0.46 ; 95 \% \\
\text { Cl: } 0.37-0.56, p<0.0001) \\
\text { ORR: } 11 \% \text { vs. } 4 \%\end{array}$ & 2017 \\
\hline Cabozantinib & $\begin{array}{l}\text { VEGFR2, c-Met, RET, c- } \\
\text { Kit, AXL, FLT3 }\end{array}$ & Second-line & NCT01908426 & $\begin{array}{l}\text { Phase III, cabozantinib } \\
\text { vs. placebo }\end{array}$ & $\begin{array}{l}\text { OS: } 10.2 \text { vs. } 8.0 \text { months (HR 0.76; } 95 \% \\
\text { Cl: } 0.63-0.92, p=0.005) \\
\text { PFS: } 5.2 \text { vs. } 1.9 \text { months (HR } 0.44 ; 95 \% \\
\text { Cl: } 0.36-0.52, p<0.001) \\
\text { ORR: } 4 \% \text { vs. }<1 \%\end{array}$ & 2019 \\
\hline Ramucirumab & VEGFR2 & Second-line & NCT02435433 & $\begin{array}{l}\text { Phase III, ramucirumab } \\
\text { vs. placebo }\end{array}$ & $\begin{array}{l}\text { OS: } 8.5 \text { vs. } 7.3 \text { months (HR } 0.71 ; 95 \% \\
\text { Cl: } 0.531-0.949, p=0.0199) \\
\text { PFS: } 2.8 \text { vs. } 1.6 \text { months (HR } 0.452 ; 95 \% \\
\text { Cl: } 0.339-0.603, p<0.0001) \\
\text { ORR: } 5 \% \text { vs. } 1 \%\end{array}$ & 2019 \\
\hline Nivolumab & PD-1 & Second-line & NCT01658878 & Phase I/II, nivolumab & $\begin{array}{l}\text { ORR: The dose-expansion phase 20\% (95\% } \\
\text { Cl: } 15-26) \\
\text { The dose-escalation phase } 15 \% \text { (95\% Cl: 6-28) }\end{array}$ & 2017 \\
\hline Pembrolizumab & PD-1 & Second-line & NCT02702414 & Phase II, pembrolizumab & $\begin{array}{l}\text { ORR: } 17 \% \\
1(1 \%) \text { complete and } 17 \text { (16\%) partial responses }\end{array}$ & 2018 \\
\hline $\begin{array}{l}\text { Nivolumab plus } \\
\text { Ipilimumab }\end{array}$ & PD-1 CTLA-4 & Second-line & NCT01658878 & $\begin{array}{l}\text { Phase I/II, Nivolumab } \\
\text { Ipilimumab }\end{array}$ & $\begin{array}{l}\text { ORR: arm A: } 32 \% \text { arm B: } 27 \% \text { arm C: } 29 \% \text { OS: } \\
\text { arm A: } 22.8 \text { months arm B: } 12.5 \text { months arm } \\
\text { C: } 12.7 \text { months }\end{array}$ & 2020 \\
\hline
\end{tabular}

HCC, hepatocellular carcinoma; VEGFR, vascular endothelial growth factor receptor; PDGFR, platelet-derived growth factor receptor; c-Kit, stem cell factor receptor; FLT3, FMS-like tyrosine kinase-3; RET, rearranged during transfection; OS, overall survival; ORR, objective response rate; FGFR, fibroblast growth factor receptor; PFS, progression-free survival; TTP, time to progression; PD-L1, programmed cell death ligand 1; VEGF, vascular endothelial growth factor; Tie-2, tyrosine kinase with immunoglobulin-like and epidermal growth factor homology domains; c-Met, hepatocyte growth factor receptor; PD-1, programmed cell death protein 1; CTLA-4, cytotoxic T-lymphocyte-associated antigen 4. 


\section{APPROVED TARGETED THERAPEUTIC AGENTS FOR HCC}

\section{First-Line Setting \\ Sorafenib}

Sorafenib is an oral multi-targeted TKI, which exerts dual antitumor effects (33). This drug not only directly suppresses tumor cells proliferation by blocking RAF/MEK/ERK and JAK/ STAT signaling pathways, but also inhibits tumor angiogenesis by targeting VEGFRs, PDGFR- $\beta$, c-Kit, FLT3, RET $(33,34)$. In the Sorafenib HCC Assessment Randomized Protocol (SHARP) trial, in comparison to placebo arm, sorafenib arm showed prolonged overall survival (OS) (10.7 months vs 7.9 months; HR 0.69; $\mathrm{p}<0.001)$ and time to radiologic progression (5.5 months vs 2.8 months; HR 0.58; p<0.001) (35). Based on the results, sorafenib was approved by FDA for the first-line treatment of advanced HCC in 2007. The similarly promising results were displayed in another phase III Oriental trial. The study also showed a significant improvement in median OS (6.5 months vs 4.2 months; HR 0.68; $\mathrm{p}=0.014)$ and time to progression (TTP) (2.8 months vs 1.4 months; HR 0.57; $\mathrm{p}=0.0005)$ in patients treated with sorafenib compared with placebo (36). Unfortunately, the treatment-related adverse events led to dose reductions in small fraction of patients and rarely needed interruptions (36).

\section{Lenvatinib}

Lenvatinib is an oral multi-kinase inhibitor targeting VEGFR1-3, FGFR1-4, PDGFR- $\alpha$, RET and c-Kit (37). Lenvatinib was approved by the FDA in 2018 as first-line treatment for advanced HCC. The approval is based on an open-label, phase III, multicenter, non-inferiority trial (38). The previous phase II clinical trial had shown positive results of lenvatinib for the treatment of HCC (39). Then, the further phase III, noninferiority trial was performed to compare the efficacy and safety of lenvatinib versus sorafenib in HCC patients (38). As first-line treatment, lenvatinib was non-inferior to sorafenib in OS (13.6 months vs 12.3 months; HR 0.92) (38). Furthermore, lenvatinib showed a significant improvement in progression-free survival (PFS) (7.4 months vs 3.7 months; HR 0.66; $\mathrm{p}<0.0001$ ) and objective response rate (ORR) (40.6\% vs 12.4\%; OR 5.01; $\mathrm{p}<0.0001)$ compared with sorafenib (38).

\section{Second-Line Setting Regorafenib}

Regorafenib primarily targets VEGFR1-3, PDGFR- $\beta$, FGFR1, Tie-2, c-Kit, RET, B-RAF (40). The FDA approved regorafenib as the second-line setting for advanced HCC in 2017 based on the results of an international, multicenter, randomized, doubleblind, placebo-controlled, phase III RESORCE trial (41). The trial aimed to assess the effectiveness and safety of regorafenib in HCC patients who progressed after sorafenib treatment (41). Regorafenib increased OS to 10.6 months from 7.8 months in the placebo arm (HR 0.63; p<0.0001) (41). Regorafenib is the first systemic therapy to show survival benefit in HCC patients who progressed on sorafenib.

\section{Cabozantinib}

Cabozantinib has dual blocking effects on VEGFR2 and c-Met, which exerts anti-tumor potential by reducing angiogenesis and suppressing cell proliferation, migration and invasion (42). The drug also has targeted inhibition of RET, c-Kit, AXL, FLT3 (43). The randomized phase III clinical trial CELESTIAL enrolled 707 patients with advanced and progressed HCC who had been previously treated with sorafenib (44). Patients in cabozantinib arm showed significantly improvement of survival compared with the placebo arm (median OS: 10.2 months vs 8.0 months; HR 0.76; $\mathrm{p}=0.005$. median PFS: 5.2 months vs 1.9 months; HR $0.44 ; \mathrm{p}<0.001)(44)$. Moreover, the ORR in cabozantinib arm was $4 \%$, higher than less than $1 \%$ in placebo arm (44). Given the survival benefits brought by cabozantinib, this drug was FDA approved as second-line setting for HCC in 2019.

\section{Ramucirumab}

Ramucirumab is a fully human IgG1 monoclonal antibody targeting VEGFR2 (45). Unlike small molecule VEGFR TKIs, ramucirumab binds to specific epitope of the extracellular domain of VEGFR2, blocking the binding of the therapeutic target to its ligand VEGF (46). A phase II study showed that ramucirumab $8 \mathrm{mg} / \mathrm{kg}$ infused intravenously every 2 weeks had anticancer activity in advanced HCC patients (47). In 2019, the FDA approved ramucirumab as monotherapy for HCC patients having alpha fetoprotein (AFP) $\geq 400 \mathrm{ng} / \mathrm{ml}$ and previously treated with sorafenib. The approval is based on the phase III REACH-2 clinical trial. This is the first positive phase III trial conducted in biomarker-selected HCC patients (48). Both the median OS (8.5 months vs 7.3 months; HR 0.710; $\mathrm{p}=0.0199$ ) and PFS (2.8 months vs 1.6 months; HR 0.452; $<<0.0001$ ) were longer in ramucirumab arm than that in placebo arm (48). However, there was no statistical difference in ORR between ramucirumab $\operatorname{arm}(5 \%)$ and placebo arm (1\%) $(\mathrm{p}=0.1697)(48)$. Ramucirumab had a manageable safety and acceptable tolerability. The incidences of serious adverse events were 35\% in ramucirumab arm and $29 \%$ in placebo arm (48).

\section{ADVANCES OF OTHER MULTI-TARGETED THERAPEUTIC AGENTS FOR HCC}

\section{Sunitinib}

Sunitinib (SU011248) is an oral multi-kinase inhibitor that targets VEGFRs, PDGFRs, c-Kit, FLT3, RET and colonystimulating factor 1 (CSF-1) (49). The multicenter phase II SAKK 77/06 trial evaluated the antitumor activity of sunitinib in advanced HCC patients (50). Patients were administrated 37.5 mg sunitinib daily until disease progression or intolerable toxicity occurred (50). The stable disease rate was $40 \%$ (50). However, another open multicenter phase II study conducted in Europe and Asia reported a low overall ORR (2.7\%) in advanced unresectable HCC patients treated with sunitinib, which did not meet the primary endpoint (expected ORR was 15\%) (51). In addition, $50 \mathrm{mg} /$ day sunitinib showed severe toxicity (51). 
Hence, phase III study of sunitinib in HCC was halted due to its toxicity.

\section{Brivanib}

Brivanib is a selective dual inhibitor targeting VEGFR and FGFR. Preclinical study had shown that brivanib significantly inhibited the growth of multiple HCC xenografts (52). Several clinical trials were conducted to evaluate the efficacy of brivanib in advanced HCC patients. In phase II studies, brivanib showed promising antitumor activity as first- or second-line therapy (53, 54). However, brivanib did not significantly improve OS of HCC patients as second-line therapy in phase III study, and another phase III study also did not meet the primary endpoint of OS noninferiority for brivanib versus sorafenib $(55,56)$.

\section{Vandetanib}

Vandetanib is an oral TKI targeting VEGFR, EGFR and RET. In a phase II, randomized, double-blind, placebo-controlled study, vandetanib showed a trend of improvement in PFS and OS for advanced HCC, but there was no statistically significant difference compared to the placebo arm. Also, the two arms had no difference in tumor stabilization rate (57). However, the combination of vandetanib with radiotherapy significantly enhanced radiation killing (58).

\section{Linifanib}

Linifanib (ABT-869) is an ATP-competitive TKI targeting all VEGFRs and PDGFR families (59). In a phase II single-arm clinical trial, linifanib showed clinical activity in advanced HCC patients who had received $\leq 1$ systemic therapy (60). An openlabel phase III clinical trial evaluated the efficacy and safety of linifanib versus sorafenib in advanced HCC patients who were not systemically treated (61). Although the linifanib arm had longer TTP, PFS and higher response rate, the study did not meet the primary endpoint, with no significant difference in OS between the linifanib and sorafenib arms (61). Moreover, patients in the linifanib arm experienced more frequent grade $\geq 3$ adverse events (61).

\section{Nintedanib}

Nintedanib (BIBF 1120) is an oral triple angiokinase inhibitor targeting VEGFR1-3, FGFR, PDGFR (62). BIBF 1120 (50 or 100 $\mathrm{mg} / \mathrm{kg} / \mathrm{d}$ ) showed anti-tumor and anti-angiogenic activity in HepG2 xenograft model (62). In a randomized, multicenter, open-label study of Asian patients with advanced HCC, the phase I portion, patients were divided into two groups based on baseline alanine aminotransferase/aspartate aminotransferase (ALT/AST) and Child-Pugh score (group I: ALT and AST $\leq 2$ times the upper limit of normal (ULN) and Child-Pugh score 56; group II: ALT or AST $>2$ to $\leq 5$ times the ULN or Child-Pugh score 7), and the maximum tolerated dose (MTD) of $200 \mathrm{mg}$ was determined for both groups (63). The phase II portion, group I patients were randomly assigned in a 2:1 ratio to nintedanib 200 mg twice daily or sorafenib $400 \mathrm{mg}$ twice daily continuously for 28 days (63). The both arms showed similar results in primary endpoint TTP (2.8 months vs 3.7 months) and the secondary endpoint OS (10.2 months vs 10.7 months) (63).

\section{Dovitinib}

Dovitinib is a multi-kinase inhibitor targeting VEGFR, PDGFR and FGFR. In addition to its anti-angiogenic effects, dovitinib induces dephosphorylation of retinoblastoma protein, upregulates p-histone $\mathrm{H} 2 \mathrm{~A}-\mathrm{X}$ and p27, and downregulates p-CDK-2 and cyclin $\mathrm{B} 1$, thereby reducing cell proliferation and inducing tumor cell apoptosis (64). In addition, dovitinib induces apoptosis of sorafenib-resistant cell lines by inhibiting signal transducer and activator of transcription 3 (STAT3) (65). Unfortunately, a randomized, open-label, phase II study of AsiaPacific patients reported that dovitinib did not show superior activity to sorafenib in first-line treatment of advanced HCC (66).

\section{Donafenib}

Donafenib is a novel TKI and similar to sorafenib. In a phase Ib clinical trial, a lower dosage of donafenib showed significant anticancer effects (TTP was 120 days) and good safety profile in Chinese patients with advanced HCC (67). The ZGDH3 study is the first completed phase II/III clinical trial in China to evaluate the efficacy of donafenib for the first-line treatment of advanced HCC. At the 56th Annual Meeting of the American Society of Clinical Oncology (ASCO 2020), the investigators presented the latest ZGDH3 findings to the world through an oral presentation. The study results showed that the primary endpoint of OS was longer in donafinib arm than sorafenib arm (12.1 months vs 10.3 months). The donafenib arm showed a trend toward better overall safety, demonstrating the potential of donafinib in targeted therapy for HCC.

\section{POTENTIAL THERAPEUTIC TARGETS AND HIGHLY SELECTIVE DRUGS FOR HCC}

\section{EGF/EGFR}

EGFR is a PTK that binds to the ligands EGF and TGF- $\alpha$ to induce receptor dimerization and autophosphorylation, which trigger the downstream MAPK, PI3K, and PLC $\gamma$ signaling pathways that mediate cell proliferation, survival, adhesion, migration, and differentiation (68-71). EGFR is overexpressed in human HCC cells (72). Some oncogenic mutations such as the L834R mutation lead to spontaneous EGFR dimerization (73). Erlotinib is an oral TKI that specifically blocks tyrosine kinase activity and autophosphorylation of EGFR (74). DCR of 59\% was observed in a phase II study of erlotinib for advanced HCC patients who had previously allowed only one systemic or local treatment (74). Bevacizumab plus erlotinib had also shown promising biological activity in the treatment of advanced HCC. In a phase II, singlearm, single-institution, investigator-initiated study, $62.5 \%$ of patients were alive and progression free at 16 weeks after the treatment of bevacizumab plus erlotinib (75). The median PFS was 39 weeks, and the median OS was 68 weeks (75).

\section{FGF19/FGFR4}

FGF19 is an important driver of HCC development. It binds to FGFR4 with high affinity $(76,77)$. Klotho-beta is a co-receptor 
for FGFR4, which is involved in the activation of FGF19/FGFR4 (78). The FGF19/FGFR4 pathway activates GSK3 $\beta / \beta$-catenin, PI3K/AKT, PLC $\gamma / D A G / P K C$, RAS/RAF/MAPK signaling cascades and promotes the survival, proliferation, and metastasis of HCC (77). A phase I study evaluated the antitumor activity of fisogatinib (BLU-554), a small molecule highly selective inhibitor targeting FGFR4 (79). The ORR in patients with FGF19-positive tumors was $17 \%$. The median duration of response (DOR) was 5.3 months, and the median PFS was 3.3 months. However, in patients with FGF19-negative tumors, the ORR was $0 \%$, and the median PFS was 2.3 months (79).

\section{Insulin-Like Growth Factor-1 (IGF-1)/IGF-1 Receptor (IGF-1R)}

The binding of ligand IGF-1 to IGF-1R stimulates the activation and phosphorylation of tyrosine kinase, which activates downstream MAPK, AKT and STAT pathways and promotes cell proliferation, migration, stemness and survival (80). Activation of the IGF axis was observed in breast cancer, sarcoma, and non-small cell lung cancer (81). In early HCCs, IGF activity correlated with mTOR signaling and HCC cells proliferation (82). Currently, at least 4 fully human IgG1 monoclonal antibodies targeting IGF-1R have been developed, including cixutumumab (83). The drug blocks phosphorylation of tyrosine residues, mediates receptor internalization and degradation, and produces antibody-dependent complementmediated cytotoxicity (ADCC) and complement-dependent cytotoxicity (CDC) effects (84). Preclinical study had shown that IGF-1R blockade inhibited the growth of HCC, but no clinically meaningful activity was observed in the phase II study $(84,85)$. Besides, the combination of cixutumumab and sorafenib also did not exhibit superior clinical efficacy in unselected ?A3B2 twb $0.24 w$ ? $>$ patients with HCC (86). The IGF-1R is reciprocally activated by NPM-ALK, suggesting that dual inhibition of IGF-1R and ALK could enhance the therapeutic effect of IGF-1R inhibitor (87). Lee reported that cixutumumab treatment activated STAT3 to induce IGF secretion, which recruited macrophages and fibroblasts and created an angiogenic and metastatic environment (88). Therefore, ongoing research elucidating mechanisms of resistance and uncovering responsive biomarkers are required for the success of IGF-1R targeted therapy.

\section{c-Met}

c-Met is an RTK, and its known ligand is HGF (89). HGF induces dimerization and activation of overexpressed c-Met, which stimulates multiple downstream signaling pathways such as MAPK, PI3K, STAT and NF kappa-B (90). In preclinical models of HCC, the HGF/c-Met inhibitor MSC2156119J inhibited tumor growth and induced complete regression (91). Tivantinib (ARQ 197), an orally administered selective c-Met inhibitor, showed antitumor activity in phase I and phase II studies $(92,93)$. However, in phase III studies, for MET-high advanced HCC patients who previously treated with sorafenib, no significantly improved PFS and OS were observed in tivantinib arm compared to the placebo arm $(94,95)$. More randomized trials are necessary to determine whether tivantinib is a potential treatment for certain subgroups of patients. Tepotinib, another highly selective c-Met inhibitor, met the primary endpoint in treating sorafenib-pretreated patients with advanced HCC, with a 12 -week PFS of $63.3 \%$ (96). The HGF/cMet and VEGF/VEGFR pathways had synergistic effects in neovascularization through enhancing intracellular signaling and modulation of signaling molecules (97). A clinical study reported that advanced HCC patients treated with the antiVEGFR2 mAb ramucirumab plus the anti-MET $\mathrm{mAb}$ emibetuzumab showed an $6.7 \%$ overall response rate, $60 \%$ DCR and 5.42 months PFS, which further supporting the results of preclinical study (98). In addition, other c-Met inhibitors such as foretinib and capmatinib also showed promising antitumor activity in advanced HCC $(99,100)$.

\section{Angiopoetin/Tie-2}

Ang-1 and Ang-2 are angiopoietins, which activate Tie-2 receptor and promote neovascularization (101). Trebananib is a peptide inhibitor that blocks the interaction of Ang-1 and Ang2 with the Tie- 2 receptor and reduces tumor angiogenesis (102). The efficacy of trebananib in combination with sorafenib for advanced HCC was evaluated in a phase II study (103). The primary endpoint of the study was planned to be a 4-month PFS of $\geq 78 \%$. It is disappointing that the study was not met the primary endpoint (103).

\section{Transforming Growth Factor- $\beta$ (TGF- $\beta$ )/ TGF- $\beta$ Receptor (TGF- $\beta R$ )}

TGF- $\beta$ is a secreted factor that leads to decreased cell adhesion, loss of polarity and tight junctions by inducing epithelial mesenchymal transition (EMT) (104). TGF- $\beta$ binds to TGF- $\beta$ R and upregulates the expression of pro-angiogenic factors such as VEGF (104). TGF- $\beta /$ Smad signaling promotes immune escape by impairing the function of cytotoxic T cells, DC cells and NK cells (104-106). These mechanisms contribute to HCC tumor progression. Galunisertib (LY2157299) is a small molecule inhibitor that selectively targets TGF- $\beta$ R. This drug demonstrated antitumor activity for second-line treatment of HCC in a phase II study (107). TGF- $\beta /$ TGF $\beta$ R signaling has been reported to confer resistance to sorafenib (108). In preclinical study, galunisertib enhanced sorafenib-induced apoptosis (108).

\section{mTOR}

mTOR is a dual-specificity kinase that catalyzes phosphorylation on serine/threonine and tyrosine residues of its substrates (109). mTORC1 and mTORC2 are two major complexes that mediate the regulation of multiple targets by mTOR (109). mTORC1 promotes anabolism of proteins and nucleotides by upregulating the expression of metabolic genes and inhibiting catabolic processes such as autophagy (110). mTORC2 phosphorylates and activates AKT (protein kinase B), PKC (protein kinase C) and SGK (serum/glucocorticoid regulated kinase) of the AGC protein kinase family, which promotes the survival and proliferation of HCC cells $(111,112)$. In addition, activated AKT phosphorylates and activates mTORC1, resulting in a positive feedback pathway loop that regulates HCC cell growth (110). Preclinical studies showed that mTOR inhibitors 
significantly inhibit growth and induce apoptosis of HCC cell lines (113-115). Everolimus given daily at $7.5 \mathrm{mg}$ showed clinical activity in advanced HCC patients in a randomized phase I/II study (116). However, in a global multicenter randomized phase III clinical study, everolimus did not improve OS of these patients (117). Treatment of HCC patients undergoing liver transplantation with mTOR-inhibitor temsirolimus for $\geq 3$ months improved survival outcomes, and the greatest benefit was observed in the subgroup with AFP $\geq 10 \mathrm{ng} / \mathrm{ml}$ (118). A phase II trial of bevacizumab plus temsirolimus for the first-line treatment of HCC reported positive results with ORR of $19 \%$ and median OS of 14 months (119). However, everolimus plus sorafenib did not demonstrate better survival benefits compared to sorafenib alone in another phase II trial (120). Combination therapy of MEK inhibitors and mTOR inhibitors exhibited enhanced antitumor effects in vivo and in vitro models of HCC (121).

\section{Hippo-Yes-Associated Protein (YAP)}

The Hippo-YAP pathway plays a prominent role in inhibiting tumor growth, especially in HCC (122). The core component of the Hippo signaling pathway, adaptor protein salvador homolog 1 (SAV1 or WW45), couples mammalian sterile 20-like kinase 1/ 2 (MST1/2)-mediated kinases large tumor suppressor homolog $1 / 2$ (LATS1/2) phosphorylation (122). This cascade leads to downstream YAP phosphorylation and retention in the cytoplasm, followed by ubiquitination and degradation (122). When Hippo-YAP signaling is attenuated, YAP and transcriptional coactivator translocate to the nucleus and initiate transcription of pro-proliferative and apoptosissuppressing genes (122). Hypoxia induces nuclear translocation and accumulation of YAP (123). CT-707 is a YAP signaling inhibitor that increases YAP phosphorylation and reduces nuclear accumulation. Both in vivo and in vitro HCC models have demonstrated potent anti-tumor activity of CT-707 (124).

\section{RAS/RAF/MEK/ERK}

Evidences suggest that the RAS/RAF/MEK/ERK pathway is hyperactive in $\operatorname{HCC}(125,126)$. Activated RAS induces phosphorylation of RAF kinase, which subsequently leads to the phosphorylation of downstream signaling factors MEK and ERK. Phosphorylated ERK dimerizes and translocates to the nucleus to participate in cell proliferation and differentiation (127). Therefore, aberrant activation of the RAS/RAF/MEK/ERK pathway may be critical for the formation and maintenance of HCC. Selumetinib is a small molecule, non-ATP competitive inhibitor that selectively targets MEK1, 2 (128). Disappointingly, in a phase II study of selumetinib for the first-line treatment of advanced HCC patients, no radiographic response was observed and the TTP was short, indicating low monotherapy activity (127). The combination of sorafenib and selumetinib for advanced HCC showed encouraging antitumor activity superior to sorafenib alone in a phase Ib study, suggesting that this combination may have a synergistic effect (129). Several clinical studies had reported that HCC patients treated with the MEK1/2 inhibitor refametinib plus sorafenib had a better clinical response relative to refametinib alone, especially those with RAS mutations $(130,131)$.

\section{STAT3}

Many cancer cells harbor constitutive activation of STAT3 (132). Phosphorylated STAT3 was detected in $60 \%$ of HCC specimens (133). Several cytokines and growth factors such as IL-6, EGF, HGF are involved in the induction of STAT3 activation (134, 135). In addition, phosphorylation of tyrosine residue is critical for STAT3 dimerization, which mediates nuclear entry and DNA binding, inducing target gene transcription (132). Besides, activation of STAT3/SNAIL signaling promotes EMT, contributing to the progression of HCC (136). STAT3 inhibitor OPB-111077 showed limited preliminary efficacy in preclinical HCC models and phase I clinical trial for second-line treatment of advanced $\operatorname{HCC}(137,138)$.

\section{Endosialin (TEM-1, CD248)}

An experiment validated the differential expression of endosialin on tumor-associated myofibroblasts and tumor vessel-associated mural cells, involving in tumor angiogenesis, adhesion to extracellular matrix (ECM) proteins and migration through matrigel $(139,140)$. Ontuxizumab (MORAb-004-001) is a humanized anti-endosialin IgG1 $\kappa$ monoclonal antibody. The first-in-human study of this drug was conducted in the US as an open-label phase I clinical study for patients with solid tumors who had failed standard chemotherapy. The study observed initial anticancer activity of ontuxizumab (141). A phase I study was subsequently initiated in Japan to confirm the efficacy, safety and tolerability of ontuxizumab in solid tumors. In this study, stable disease rate of $53.3 \%$ and tumor shrinkage of $33.3 \%$ were observed in HCC patients (142).

\section{Endoglin (CD105)}

Endoglin (CD105) is highly expressed on active endothelial cells (143). Endoglin is involved in angiogenesis, inflammation and cancer-associated fibroblast (CAF) accumulation in the tumor microenvironment (TME) (143). TRC105 is a chimeric IgG1 $\mathrm{mAb}$ that competitively blocks the binding of endoglin to its ligand bone morphogenetic protein (BMP) and inhibits tumor angiogenesis (144). TRC105 alone lacked significant clinical activity in the treatment of HCC (145). However, TRC105 in combination with sorafenib showed encouraging activity in firstline treatment of HCC (partial response rate was 25\%) (146).

\section{Cyclin-Dependent Kinase 4/6 (CDK4/6)}

CDK4/6 promotes the cell cycle progression $(147,148)$. CDK4/6 amplification has been found in multiple malignant tumors (149-151). Palbociclib (PD-0332991) is a selective CDK4/6 inhibitor that induces reversible cell cycle arrest in human HCC lines and is efficacious in multiple preclinical models of HCC (152). In vivo model, palbociclib in combination with sorafenib was more efficacious than sorafenib alone (152). Another CDK4/6 inhibitor, ribociclib, showed similar antitumor activity in preclinical study (153). 


\section{Histone Deacetylases (HDAC)}

HDAC reversibly regulates acetylation of histones and nonhistones. Dysregulation and mutation of HDAC lead to abnormal cell proliferation, EMT and tumor angiogenesis (154). Resminostat is a HDAC inhibitor. In the SHELTER study, the combination of resminostat and sorafenib prolonged median TTP and OS compared with resminostat alone (155). However, in comparison of this combination with sorafenib monotherapy for East Asia advanced HCC patients, no significant efficacy advantage was observed in the combination arm (156).

\section{COMBINATION THERAPY OF TARGETED THERAPY AND ICI}

ICIs is a novel therapeutic approach that differs from conventional treatment mechanisms (157). It restores the viability of tumor-specific $\mathrm{T}$ cells and utilizes the host immune system to kill tumors $(158,159)$. Among many ICIs identified, anti-PD1/PD-L1 and anti-CTLA-4 are currently approved for clinical application, and combination treatment of anti-PD1 and anti-CTLA-4 could have synergistic effect in some kinds of cancer (160-163). PD-L1 expression and tumor mutational burden are widely used molecular marker to guide ICI therapy, but the predictive value is not consistent among different cancers $(164,165)$. The combination of targeted therapy with ICI shown more potent efficacy (Table 2) $(32,166)$.

Encouraging results from the CheckMate-040 (167) and KEYNOTE-224 (168) studies led to accelerated FDA approval of nivolumab and pembrolizumab as second-line therapy for advanced HCC. Further, combination of targeted therapy with immunotherapy becomes mainstream, especially antiangiogenesis therapy and ICI (169). In multiple mice models, combinations of ICI with anti-angiogenesis agents significantly increase the active anti-tumor immune cell and reduce the immune inhibitory components in comparison with ICI alone. At present, it is well accepted that combination therapy of ICI and anti-angiogenesis could achieve superior efficacy to monotherapy in several types of solid cancer (170). Atezolizumab is a highaffinity human monoclonal IgG1 antibody that specifically targets PD-L1 and blocks its interaction with PD-1 and B7.1, recovering pre-existing anti-tumor immunity $(164,171)$. Bevacizumab is an anti-VEGF monoclonal antibody (172). In a phase II trial, 13\% ORR was observed in bevacizumab-treated patients with unresectable, nonmetastatic HCC (172). Results from a multiarm phase Ib GO30140 study suggested atezolizumab plus bevacizumab had a more significant PFS benefit than atezolizumab alone (173). On May 29, 2020, the FDA approved atezolizumab plus bevacizumab as the first-line setting for patients with unresectable or metastatic HCC. Approval was granted following the results of phase III IMbrave150 trial (32). This trial assessed the efficacy of atezolizumab plus bevacizumab versus sorafenib and demonstrated that atezolizumab plus bevacizumab arm had higher 12-month OS (67.2\% vs 54.6\%) and longer PFS (6.8 months vs 4.3 months; HR 0.59; $p<0.001$ ) than sorafenib arm (32). The incidences of grade $3 / 4$ adverse events were $56.5 \%$ with atezolizumab-bevacizumab and $55.1 \%$ with sorafenib (32). Approval of atezolizumab plus bevacizumab is likely to change the paradigm of the treatment of HCC. In a phase Ib study, lenvatinib plus the anti-PD-1 mAb pembrolizumab had

TABLE 2 | Current clinical trials investigating the combination therapy of targeted agents and ICls for HCC.

\begin{tabular}{|c|c|c|c|c|c|}
\hline Study design & ClinicalTrials.gov Identifier & Phase & Line & Primary end point & Study status \\
\hline SHR-1210 + Apatinib & NCT04014101 & $\|$ & First & ORR & Recruiting \\
\hline SHR-1210 + Apatinib & NCT03463876 & $\|$ & Second & ORR & Active, not recruiting \\
\hline AK104 + Lenvatinib & NCT04444167 & $\mathrm{lb} / \mathrm{ll}$ & First & ORR & Recruiting \\
\hline Nivolumab + Bevacizumab vs. Nivolumab vs. Bevacizumab & NCT04393220 & $\|$ & First & PFS/OS & Recruiting \\
\hline Pembrolizumab + Regorafenib & NCT04696055 & $\|$ & Second & ORR & Recruiting \\
\hline Nivolumab + Galunisertib & NCT02423343 & $|/| \mid$ & Second & MTD & Completed \\
\hline Toripalimab + ATG-008 & NCT04337463 & I & Second & MTD/RP2D/ORR & Recruiting \\
\hline HLX10 + HLX04 & NCT03973112 & $\|$ & Second & ORR & Recruiting \\
\hline HX008+Bevacizumab vs. HX008 + Lenvatinib & NCT04741165 & $\|$ & First & ORR & Recruiting \\
\hline Sintilimab + Lenvatinib & NCT04042805 & $\|$ & First & ORR & Recruiting \\
\hline Toripalimab + Lenvatinib & NCT04368078 & $\|$ & Second & ORR & Recruiting \\
\hline Toripalimab + Bevacizumab & NCT04605796 & $\|$ & First & ORR/Safety & Recruiting \\
\hline Camrelizumab + Lenvatinib & NCT04443309 & $|/| \mid$ & First & ORR & Recruiting \\
\hline Camrelizumab + Apatinib & NCT04701060 & $\|$ & First & ORR & Recruiting \\
\hline Tislelizumab + regorafenib vs. regorafenib & NCT04183088 & $\|$ & First & ORR/PFS & Recruiting \\
\hline MK-1308A + Lenvatinib & NCT04740307 & $\|$ & First & ORR & Recruiting \\
\hline Pembrolizumab + Lenvatinib vs. Lenvatinib + placeco & NCT03713593 & III & First & PFS/OS & Active, not recruiting \\
\hline Nivolumab + Lenvatinib & NCT03841201 & $\|$ & First & ORR/Safety & Recruiting \\
\hline PDR001 + Sorafenib & NCT02988440 & 1 & First & AE/DLT & Completed \\
\hline Atezolizumab + Bevacizumab & NCT04102098 & III & First & RFS & Recruiting \\
\hline Avelumab + Axitinib & NCT03289533 & I & First & $\mathrm{AE}$ & Completed \\
\hline Atezolizumab + Cabozantinib vs. sorafenib & NCT03755791 & III & First & PFS/OS & Recruiting \\
\hline Durvalumab + Tivozanib & NCT03970616 & $|/| \mid$ & First & $\mathrm{AE}$ & Recruiting \\
\hline Durvalumab + Bevacizumab vs. Durvalumab & NCT03847428 & \|\| & First & RFS & Recruiting \\
\hline
\end{tabular}

ICls, immune checkpoint inhibitors; HCC, hepatocellular carcinoma; ORR, objective response rate; PFS, progression-free survival; OS, overall survival; MTD, maximum tolerated dose; $R P 2 D$, recommended phase II dose; $A E$, adverse event; $D L T$, dose limited toxicity; $R F S$, recurrence-free survival. 
promising anticancer activity in advanced HCC. The ORR and DOR were $46.0 \%$ and 8.6 months, respectively. The median PFS and OS were 8.6 months and 22 months, respectively (174). The combination of ramucirumab and the anti-PD-L1 mAb durvalumab also showed promising results in a phase Ia/b openlabel study of advanced HCC. The ORR was $11 \%$. The median PFS and OS were 4.4 and 10.7 months, respectively (175). SHR-1210 (anti-PD-1 antibody) $200 \mathrm{mg}$ every 2 weeks plus apatinib $250 \mathrm{mg}$ daily exhibited encouraging clinical activity in advanced HCC in an open, dose-escalation and extension study (176). The ORR was $30.8 \%$ and partial response was achieved in 8 of 16 evaluable HCC patients (176). Clinical trials of other targeted drugs in combination with ICIs are also underway. In ASCO 2021, the preliminary results of some ongoing clinical trials showed that combination therapies of ICIs with anlotinib had superior efficacies to monotherapies $(177,178)$. In addition, studies demonstrated that PARP inhibitors could also enhance the efficacy of ICIs by promoting antigen presentation and modifying immune microenvironment, leading to the enhanced tumor-killing activities of T cell (179).

\section{CONCLUSION AND PERSPECTIVE}

Advanced HCC is a major challenge in cancer treatment. Sorafenib is the first FDA-approved TKI for the first-line treatment of advanced HCC, bringing a breakthrough to the treatment challenge. Based on the promising results in clinical studies, other molecularly targeted drugs such as lenvatinib, regorafenib, cabozantinib, ramucirumab also have been approved by FDA for first- or second-line treatment of advanced HCC. However, the efficacy is far from being satisfied. Therefore, new targets are extensively explored. In addition to interfering with the interaction between PTK and ligand, blocking the downstream signaling pathway of PTK cascade also exhibits effective inhibition of HCC progression, such as mTOR inhibitors, MEK inhibitors and STAT3 inhibitors. Besides, targeted inhibitors acting on cell cycle progression also show antitumor potential in preclinical studies of HCC. Following the research advance, potential target for HCC continues to be uncovered. For example, a recent study demonstrated that p38 MAPK gamma induced mouse hepatocyte proliferation after partial hepatectomy by promoting the phosphorylation of retinoblastoma protein as CDK-like kinase. Moreover, p38 $\gamma$ was required for the chemically induced formation of liver tumors (180). Sterol o-acyltransferase1 (SOAT1) and carnitine palmitoyltransferase 1A (CPT1A) were

\section{REFERENCES}

1. Bray F, Ferlay J, Soerjomataram I, Siegel RL, Torre LA, Jemal A. Global Cancer Statistics 2018: GLOBOCAN Estimates of Incidence and Mortality Worldwide for 36 Cancers in 185 Countries. CA Cancer J Clin (2018) 68:394-424. doi: 10.3322/caac.21492

2. Yang JD, Roberts LR. Hepatocellular Carcinoma: A Global View. Nat Rev Gastroenterol Hepatol (2010) 7:448-58. doi: 10.1038/nrgastro. 2010.100 found to regulate fatty acid metabolism, and simultaneously targeting SOAT1 and CPT1A demonstrated synergistic anticancer efficacy in HCC in vitro and in vivo models (181). Liu et al. applied multi-omics technology to characterize tumor microenvironment and defined HCC into three immune subtypes. Their study suggested that MMP-9 reflected immune features and might be a valuable predictor of immunotherapeutic response in HCC (182).

Despite impressive progress in targeted therapy for advanced HCC, several challenges remain. One is drug-related adverse events, which lead to dose reduction, interruption or discontinuation. Besides, drug resistance remains a major cause of the failure of targeted therapy. The underlying mechanisms may be tumor heterogeneity and clonal evolution. In addition, there is a lack of reliable biomarkers to identify the HCC patients most likely to benefit from targeted therapy. Some circulating markers, such as AFP, IL- 6 and TNF- $\alpha$, correlate with the treatment outcomes of HCC (183-185), but large prospective studies are required to validate the preliminary findings. How to overcome these challenges and explore low-toxic and efficient treatment strategies are the direction of effort.

Single drug activity is insufficient and a rational combination of different drugs is needed to obtain maximum benefit. The combination of targeted therapy plus ICI has attracted attention, with positive results in several clinical trials. In the future, the integration of multidisciplinary treatment approaches for advanced HCC and the development of personalized treatment plans based on the disease status of HCC will contribute to the progress of precision medicine.

\section{AUTHOR CONTRIBUTIONS}

MN drafted the manuscript and prepared the figure and tables. MY and NL helped in revising it critically for important intellectual content. KJW and KMW designed this review and revised the manuscript. All authors contributed to the article and approved the submitted version.

\section{FUNDING}

This work was supported by the National Natural Science Foundation of China (No.81874120, 82073370).
3. Karagozian R, Derdák Z, Baffy G. Obesity-Associated Mechanisms of Hepatocarcinogenesis. Metabolism (2014) 63:607-17. doi: 10.1016/ j.metabol.2014.01.011

4. Dal Bo M, De Mattia E, Baboci L, Mezzalira S, Cecchin E, Assaraf YG, et al. New Insights Into the Pharmacological, Immunological, and CAR-TCell Approaches in the Treatment of Hepatocellular Carcinoma. Drug Resist Updat (2020) 51:100702. doi: 10.1016/j.drup.2020.100702

5. Forner A, Reig M, Bruix J. Hepatocellular Carcinoma. Lancet (2018) 391:1301-14. doi: 10.1016/s0140-6736(18)30010-2 
6. European Organisation For Research And Treatment Of Cancer. EASL-EORTC Clinical Practice Guidelines: Management of Hepatocellular Carcinoma. J Hepatol (2012) 56:908-43. doi: 10.1016/ j.jhep.2011.12.001

7. Yang JD, Hainaut P, Gores GJ, Amadou A, Plymoth A, Roberts LR. A Global View of Hepatocellular Carcinoma: Trends, Risk, Prevention and Management. Nat Rev Gastroenterol Hepatol (2019) 16:589-604. doi: 10.1038/s41575-019-0186-y

8. Tabrizian P, Jibara G, Shrager B, Schwartz M, Roayaie S. Recurrence of Hepatocellular Cancer After Resection: Patterns, Treatments, and Prognosis. Ann Surg (2015) 261:947-55. doi: 10.1097/sla.000000 0000000710

9. Park W, Chung YH, Kim JA, Jin YJ, Lee D, Shim JH, et al. Recurrences of Hepatocellular Carcinoma Following Complete Remission by Transarterial Chemoembolization or Radiofrequency Therapy: Focused on the Recurrence Patterns. Hepatol Res (2013) 43:1304-12. doi: 10.1111/ hepr. 12083

10. Foerster F, Hoppe-Lotichius M, Vollmar J, Marquardt JU, Weinmann A, Wörns MA, et al. Long-Term Observation of Hepatocellular Carcinoma Recurrence After Liver Transplantation at a European Transplantation Centre. United Eur Gastroenterol J (2019) 7:838-49. doi: 10.1177/ 2050640619840221

11. Portolani N, Coniglio A, Ghidoni S, Giovanelli M, Benetti A, Tiberio GA, et al. Early and Late Recurrence After Liver Resection for Hepatocellular Carcinoma: Prognostic and Therapeutic Implications. Ann Surg (2006) 243:229-35. doi: 10.1097/01.sla.0000197706.21803.a1

12. Lee JO, Lee KW, Oh DY, Kim JH, Im SA, Kim TY, et al. Combination Chemotherapy With Capecitabine and Cisplatin for Patients With Metastatic Hepatocellular Carcinoma. Ann Oncol (2009) 20:1402-7. doi: 10.1093/annonc/mdp010

13. Schulze K, Imbeaud S, Letouzé E, Alexandrov LB, Calderaro J, Rebouissou S, et al. Exome Sequencing of Hepatocellular Carcinomas Identifies New Mutational Signatures and Potential Therapeutic Targets. Nat Genet (2015) 47:505-11. doi: 10.1038/ng.3252

14. Cancer Genome Atlas Research Network. Comprehensive and Integrative Genomic Characterization of Hepatocellular Carcinoma. Cell (2017) 169:1327-41.e23. doi: 10.1016/j.cell.2017.05.046

15. Su X, Zhao L, Shi Y, Zhang R, Long Q, Bai S, et al. Clonal Evolution in Liver Cancer at Single-Cell and Single-Variant Resolution. J Hematol Oncol (2021) 14:22. doi: 10.1186/s13045-021-01036-y

16. Gotink KJ, Verheul HM. Anti-Angiogenic Tyrosine Kinase Inhibitors: What Is Their Mechanism of Action? Angiogenesis (2010) 13:1-14. doi: 10.1007/ s10456-009-9160-6

17. Jiao Q, Bi L, Ren Y, Song S, Wang Q, Wang YS. Advances in Studies of Tyrosine Kinase Inhibitors and Their Acquired Resistance. Mol Cancer (2018) 17:36. doi: 10.1186/s12943-018-0801-5

18. Regad T. Targeting RTK Signaling Pathways in Cancer. Cancers (Basel) (2015) 7:1758-84. doi: 10.3390/cancers7030860

19. Jeltsch M, Leppänen VM, Saharinen P, Alitalo K. Receptor Tyrosine KinaseMediated Angiogenesis. Cold Spring Harb Perspect Biol (2013) 5:a009183. doi: 10.1101/cshperspect.a009183

20. Robinson DR, Wu YM, Lin SF. The Protein Tyrosine Kinase Family of the Human Genome. Oncogene (2000) 19:5548-57. doi: 10.1038/sj.onc. 1203957

21. Liu Q, Yu S, Zhao W, Qin S, Chu Q, Wu K. EGFR-TKIs Resistance via EGFR-Independent Signaling Pathways. Mol Cancer (2018) 17:53. doi: 10.1186/s12943-018-0793-1

22. Drake JM, Lee JK, Witte ON. Clinical Targeting of Mutated and Wild-Type Protein Tyrosine Kinases in Cancer. Mol Cell Biol (2014) 34:1722-32. doi: 10.1128/mcb.01592-13

23. Lemmon MA, Schlessinger J. Cell Signaling by Receptor Tyrosine Kinases. Cell (2010) 141:1117-34. doi: 10.1016/j.cell.2010.06.011

24. Gong J, Chuang J, Cho M, Toomey K, Hendifar A, Li D. Molecular Targets, Pathways, and Therapeutic Implications for Hepatocellular Carcinoma. Int $J$ Mol Sci (2020) 21:5232. doi: 10.3390/ijms21155232

25. Cervello M, Emma MR, Augello G, Cusimano A, Giannitrapani L, Soresi M, et al. New Landscapes and Horizons in Hepatocellular Carcinoma Therapy. Aging (Albany NY) (2020) 12:3053-94. doi: 10.18632/aging.102777
26. Llovet JM, Montal R, Sia D, Finn RS. Molecular Therapies and Precision Medicine for Hepatocellular Carcinoma. Nat Rev Clin Oncol (2018) 15:599_ 616. doi: 10.1038/s41571-018-0073-4

27. Zhu XD, Sun HC. Emerging Agents and Regimens for Hepatocellular Carcinoma. J Hematol Oncol (2019) 12:110. doi: 10.1186/s13045-0190794-6

28. Akula SM, Abrams SL, Steelman LS, Emma MR, Augello G, Cusimano A, et al. RAS/RAF/MEK/ERK, PI3K/PTEN/AKT/mTORC1 and TP53 Pathways and Regulatory miRs as Therapeutic Targets in Hepatocellular Carcinoma. Expert Opin Ther Targ (2019) 23:915-29. doi: 10.1080/ 14728222.2019 .1685501

29. Llovet JM, Villanueva A, Lachenmayer A, Finn RS. Advances in Targeted Therapies for Hepatocellular Carcinoma in the Genomic Era. Nat Rev Clin Oncol (2015) 12:408-24. doi: 10.1038/nrclinonc.2015.103

30. Berretta M, Rinaldi L, Di Benedetto F, Lleshi A, De Re V, Facchini G, et al. Angiogenesis Inhibitors for the Treatment of Hepatocellular Carcinoma. Front Pharmacol (2016) 7:428. doi: 10.3389/fphar.2016.00428

31. Chen S, Cao Q, Wen W, Wang H. Targeted Therapy for Hepatocellular Carcinoma: Challenges and Opportunities. Cancer Lett (2019) 460:1-9. doi: 10.1016/j.canlet.2019.114428

32. Finn RS, Qin S, Ikeda M, Galle PR, Ducreux M, Kim TY, et al. Atezolizumab Plus Bevacizumab in Unresectable Hepatocellular Carcinoma. N Engl J Med (2020) 382:1894-905. doi: 10.1056/NEJMoa1915745

33. Wilhelm S, Carter C, Lynch M, Lowinger T, Dumas J, Smith RA, et al. Discovery and Development of Sorafenib: A Multikinase Inhibitor for Treating Cancer. Nat Rev Drug Discov (2006) 5:835-44. doi: 10.1038/ $\operatorname{nrd} 2130$

34. Tai WT, Cheng AL, Shiau CW, Huang HP, Huang JW, Chen PJ, et al. Signal Transducer and Activator of Transcription 3 Is a Major Kinase-Independent Target of Sorafenib in Hepatocellular Carcinoma. J Hepatol (2011) 55:10418. doi: 10.1016/j.jhep.2011.01.047

35. Llovet JM, Ricci S, Mazzaferro V, Hilgard P, Gane E, Blanc JF, et al. Sorafenib in Advanced Hepatocellular Carcinoma. N Engl J Med (2008) 359:378-90. doi: 10.1056/NEJMoa0708857

36. Cheng AL, Kang YK, Chen Z, Tsao CJ, Qin S, Kim JS, et al. Efficacy and Safety of Sorafenib in Patients in the Asia-Pacific Region With Advanced Hepatocellular Carcinoma: A Phase III Randomised, Double-Blind, PlaceboControlled Trial. Lancet Oncol (2009) 10:25-34. doi: 10.1016/s1470-2045 (08)70285-7

37. Yamamoto Y, Matsui J, Matsushima T, Obaishi H, Miyazaki K, Nakamura $\mathrm{K}$, et al. Lenvatinib, an Angiogenesis Inhibitor Targeting VEGFR/FGFR, Shows Broad Antitumor Activity in Human Tumor Xenograft Models Associated With Microvessel Density and Pericyte Coverage. Vasc Cell (2014) 6:18. doi: 10.1186/2045-824x-6-18

38. Kudo M, Finn RS, Qin S, Han KH, Ikeda K, Piscaglia F, et al. Lenvatinib Versus Sorafenib in First-Line Treatment of Patients With Unresectable Hepatocellular Carcinoma: A Randomised Phase 3 Non-Inferiority Trial. Lancet (2018) 391:1163-73. doi: 10.1016/s0140-6736(18)30207-1

39. Ikeda K, Kudo M, Kawazoe S, Osaki Y, Ikeda M, Okusaka T, et al. Phase 2 Study of Lenvatinib in Patients With Advanced Hepatocellular Carcinoma. J Gastroenterol (2017) 52:512-9. doi: 10.1007/s00535-016-1263-4

40. Wilhelm SM, Dumas J, Adnane L, Lynch M, Carter CA, Schütz G, et al. Regorafenib (BAY 73-4506): A New Oral Multikinase Inhibitor of Angiogenic, Stromal and Oncogenic Receptor Tyrosine Kinases With Potent Preclinical Antitumor Activity. Int J Cancer (2011) 129:245-55. doi: 10.1002/ijc. 25864

41. Bruix J, Qin S, Merle P, Granito A, Huang YH, Bodoky G, et al. Regorafenib for Patients With Hepatocellular Carcinoma Who Progressed on Sorafenib Treatment (RESORCE): A Randomised, Double-Blind, Placebo-Controlled, Phase 3 Trial. Lancet (2017) 389:56-66. doi: 10.1016/s0140-6736(16)32453-9

42. Xiang Q, Chen W, Ren M, Wang J, Zhang H, Deng DY, et al. Cabozantinib Suppresses Tumor Growth and Metastasis in Hepatocellular Carcinoma by a Dual Blockade of VEGFR2 and MET. Clin Cancer Res (2014) 20:2959-70. doi: 10.1158/1078-0432.Ccr-13-2620

43. Yakes FM, Chen J, Tan J, Yamaguchi K, Shi Y, Yu P, et al. Cabozantinib (XL184), A Novel MET and VEGFR2 Inhibitor, Simultaneously Suppresses Metastasis, Angiogenesis, and Tumor Growth. Mol Cancer Ther (2011) 10:2298-308. doi: 10.1158/1535-7163.Mct-11-0264 
44. Abou-Alfa GK, Meyer T, Cheng AL, El-Khoueiry AB, Rimassa L, Ryoo BY, et al. Cabozantinib in Patients With Advanced and Progressing Hepatocellular Carcinoma. N Engl J Med (2018) 379:54-63. doi: 10.1056/ NEJMoa1717002

45. Spratlin JL, Cohen RB, Eadens M, Gore L, Camidge DR, Diab S, et al. Phase I Pharmacologic and Biologic Study of Ramucirumab (IMC-1121B), A Fully Human Immunoglobulin G1 Monoclonal Antibody Targeting the Vascular Endothelial Growth Factor Receptor-2. J Clin Oncol (2010) 28:780-7. doi: 10.1200/jco.2009.23.7537

46. Lu D, Jimenez X, Zhang H, Bohlen P, Witte L, Zhu Z. Selection of High Affinity Human Neutralizing Antibodies to VEGFR2 From a Large Antibody Phage Display Library for Antiangiogenesis Therapy. Int J Cancer (2002) 97:393-9. doi: 10.1002/ijc.1634

47. Zhu AX, Finn RS, Mulcahy M, Gurtler J, Sun W, Schwartz JD, et al. A Phase II and Biomarker Study of Ramucirumab, a Human Monoclonal Antibody Targeting the VEGF Receptor-2, as First-Line Monotherapy in Patients With Advanced Hepatocellular Cancer. Clin Cancer Res (2013) 19:6614-23. doi: 10.1158/1078-0432.Ccr-13-1442

48. Zhu AX, Kang YK, Yen CJ, Finn RS, Galle PR, Llovet JM, et al. Ramucirumab After Sorafenib in Patients With Advanced Hepatocellular Carcinoma and Increased $\alpha$-Fetoprotein Concentrations (REACH-2): A Randomised, Double-Blind, Placebo-Controlled, Phase 3 Trial. Lancet Oncol (2019) 20:282-96. doi: 10.1016/s1470-2045(18)30937-9

49. Chow LQ, Eckhardt SG. Sunitinib: From Rational Design to Clinical Efficacy. J Clin Oncol (2007) 25:884-96. doi: 10.1200/jco.2006.06.3602

50. Koeberle D, Montemurro M, Samaras P, Majno P, Simcock M, Limacher A, et al. Continuous Sunitinib Treatment in Patients With Advanced Hepatocellular Carcinoma: A Swiss Group for Clinical Cancer Research (SAKK) and Swiss Association for the Study of the Liver (SASL) Multicenter Phase II Trial (SAKK 77/06). Oncologist (2010) 15:285-92. doi: 10.1634/ theoncologist.2009-0316

51. Faivre S, Raymond E, Boucher E, Douillard J, Lim HY, Kim JS, et al. Safety and Efficacy of Sunitinib in Patients With Advanced Hepatocellular Carcinoma: An Open-Label, Multicentre, Phase II Study. Lancet Oncol (2009) 10:794-800. doi: 10.1016/s1470-2045(09)70171-8

52. Huynh H, Ngo VC, Fargnoli J, Ayers M, Soo KC, Koong HN, et al. Brivanib Alaninate, a Dual Inhibitor of Vascular Endothelial Growth Factor Receptor and Fibroblast Growth Factor Receptor Tyrosine Kinases, Induces Growth Inhibition in Mouse Models of Human Hepatocellular Carcinoma. Clin Cancer Res (2008) 14:6146-53. doi: 10.1158/1078-0432.Ccr-08-0509

53. Finn RS, Kang YK, Mulcahy M, Polite BN, Lim HY, Walters I, et al. Phase II, Open-Label Study of Brivanib as Second-Line Therapy in Patients With Advanced Hepatocellular Carcinoma. Clin Cancer Res (2012) 18:2090-8. doi: 10.1158/1078-0432.Ccr-11-1991

54. Park JW, Finn RS, Kim JS, Karwal M, Li RK, Ismail F, et al. Phase II, OpenLabel Study of Brivanib as First-Line Therapy in Patients With Advanced Hepatocellular Carcinoma. Clin Cancer Res (2011) 17:1973-83. doi: 10.1158/ 1078-0432.Ccr-10-2011

55. Llovet JM, Decaens T, Raoul JL, Boucher E, Kudo M, Chang C, et al. Brivanib in Patients With Advanced Hepatocellular Carcinoma Who Were Intolerant to Sorafenib or for Whom Sorafenib Failed: Results From the Randomized Phase III BRISK-PS Study. J Clin Oncol (2013) 31:3509-16. doi: 10.1200/ jco.2012.47.3009

56. Johnson PJ, Qin S, Park JW, Poon RT, Raoul JL, Philip PA, et al. Brivanib Versus Sorafenib as First-Line Therapy in Patients With Unresectable, Advanced Hepatocellular Carcinoma: Results From the Randomized Phase III BRISK-FL Study. J Clin Oncol (2013) 31:3517-24. doi: 10.1200/ jco.2012.48.4410

57. Hsu C, Yang TS, Huo TI, Hsieh RK, Yu CW, Hwang WS, et al. Vandetanib in Patients With Inoperable Hepatocellular Carcinoma: A Phase II, Randomized, Double-Blind, Placebo-Controlled Study. J Hepatol (2012) 56:1097-103. doi: 10.1016/j.jhep.2011.12.013

58. Znati S, Carter R, Vasquez M, Westhorpe A, Shahbakhti H, Prince J, et al. Radiosensitisation of Hepatocellular Carcinomacells by Vandetanib. Cancers (Basel) (2020) 12:1878. doi: 10.3390/cancers12071878

59. Zhou J, Goh BC, Albert DH, Chen CS. ABT-869, a Promising MultiTargeted Tyrosine Kinase Inhibitor: From Bench to Bedside. J Hematol Oncol (2009) 2:33. doi: 10.1186/1756-8722-2-33
60. Toh HC, Chen PJ, Carr BI, Knox JJ, Gill S, Ansell P, et al. Phase 2 Trial of Linifanib (ABT-869) in Patients With Unresectable or Metastatic Hepatocellular Carcinoma. Cancer (2013) 119:380-7. doi: 10.1002/cncr.27758

61. Cainap C, Qin S, Huang WT, Chung IJ, Pan H, Cheng Y, et al. Linifanib Versus Sorafenib in Patients With Advanced Hepatocellular Carcinoma: Results of a Randomized Phase III Trial. J Clin Oncol (2015) 33:172-9. doi: $10.1200 /$ jco.2013.54.3298

62. Kudo K, Arao T, Tanaka K, Nagai T, Furuta K, Sakai K, et al. Antitumor Activity of BIBF 1120, a Triple Angiokinase Inhibitor, and Use of VEGFR2 $+\mathrm{pTyr}+$ Peripheral Blood Leukocytes as a Pharmacodynamic Biomarker In Vivo. Clin Cancer Res (2011) 17:1373-81. doi: 10.1158/1078-0432.Ccr-092755

63. Yen CJ, Kim TY, Feng YH, Chao Y, Lin DY, Ryoo BY, et al. A Phase I/ randomized Phase II Study to Evaluate the Safety, Pharmacokinetics, and Efficacy of Nintedanib Versus Sorafenib in Asian Patients With Advanced Hepatocellular Carcinoma. Liver Cancer (2018) 7:165-78. doi: 10.1159/ 000486460

64. Huynh H, Chow PK, Tai WM, Choo SP, Chung AY, Ong HS, et al. Dovitinib Demonstrates Antitumor and Antimetastatic Activities in Xenograft Models of Hepatocellular Carcinoma. J Hepatol (2012) 56:595-601. doi: 10.1016/ j.jhep.2011.09.017

65. Tai WT, Cheng AL, Shiau CW, Liu CY, Ko CH, Lin MW, et al. Dovitinib Induces Apoptosis and Overcomes Sorafenib Resistance in Hepatocellular Carcinoma Through SHP-1-Mediated Inhibition of STAT3. Mol Cancer Ther (2012) 11:452-63. doi: 10.1158/1535-7163.Mct-11-0412

66. Cheng AL, Thongprasert S, Lim HY, Sukeepaisarnjaroen W, Yang TS, Wu CC, et al. Randomized, Open-Label Phase 2 Study Comparing Frontline Dovitinib Versus Sorafenib in Patients With Advanced Hepatocellular Carcinoma. Hepatology (2016) 64:774-84. doi: 10.1002/hep.28600

67. Liu J, Li X, Zhang H, Chen G, Chen H, Hu Y, et al. Safety, Pharmacokinetics and Efficacy of Donafenib in Treating Advanced Hepatocellular Carcinoma: Report From a Phase 1b Trial. Pharmazie (2019) 74:688-93. doi: 10.1691/ ph.2019.9626

68. Ogiso H, Ishitani R, Nureki O, Fukai S, Yamanaka M, Kim JH, et al. Crystal Structure of the Complex of Human Epidermal Growth Factor and Receptor Extracellular Domains. Cell (2002) 110:775-87. doi: 10.1016/s0092-8674(02) 00963-7

69. Yarden Y. The EGFR Family and Its Ligands in Human Cancer. Signalling Mechanisms and Therapeutic Opportunities. Eur J Cancer (2001) 37(Suppl 4):S3-8. doi: 10.1016/s0959-8049(01)00230-1

70. Tomas A, Futter CE, Eden ER. EGF Receptor Trafficking: Consequences for Signaling and Cancer. Trends Cell Biol (2014) 24:26-34. doi: 10.1016/ j.tcb.2013.11.002

71. Caballero-Díaz D, Bertran E, Peñuelas-Haro I, Moreno-Càceres J, Malfettone A, López-Luque J, et al. Clathrin Switches Transforming Growth Factor- $\beta$ Role to Pro-Tumorigenic in Liver Cancer. J Hepatol (2020) 72:125-34. doi: 10.1016/j.jhep.2019.09.012

72. Ito $\mathrm{Y}$, Takeda $\mathrm{T}$, Sakon M, Tsujimoto M, Higashiyama S, Noda K, et al. Expression and Clinical Significance of Erb-B Receptor Family in Hepatocellular Carcinoma. Br J Cancer (2001) 84:1377-83. doi: 10.1054/ bjoc. 2000.1580

73. Shan Y, Eastwood MP, Zhang X, Kim ET, Arkhipov A, Dror RO, et al. Oncogenic Mutations Counteract Intrinsic Disorder in the EGFR Kinase and Promote Receptor Dimerization. Cell (2012) 149:860-70. doi: 10.1016/ j.cell.2012.02.063

74. Philip PA, Mahoney MR, Allmer C, Thomas J, Pitot HC, Kim G, et al. Phase II Study of Erlotinib (OSI-774) in Patients With Advanced Hepatocellular Cancer. J Clin Oncol (2005) 23:6657-63. doi: 10.1200/jco.2005.14.696

75. Thomas MB, Morris JS, Chadha R, Iwasaki M, Kaur H, Lin E, et al. Phase II Trial of the Combination of Bevacizumab and Erlotinib in Patients Who Have Advanced Hepatocellular Carcinoma. J Clin Oncol (2009) 27:843-50. doi: $10.1200 /$ jco.2008.18.3301

76. Sawey ET, Chanrion M, Cai C, Wu G, Zhang J, Zender L, et al. Identification of a Therapeutic Strategy Targeting Amplified FGF19 in Liver Cancer by Oncogenomic Screening. Cancer Cell (2011) 19:347-58. doi: 10.1016/ j.ccr.2011.01.040

77. Raja A, Park I, Haq F, Ahn SM. FGF19-FGFR4 Signaling in Hepatocellular Carcinoma. Cells (2019) 8:536. doi: 10.3390/cells8060536 
78. Poh W, Wong W, Ong H, Aung MO, Lim SG, Chua BT, et al. Klotho-Beta Overexpression as a Novel Target for Suppressing Proliferation and Fibroblast Growth Factor Receptor-4 Signaling in Hepatocellular Carcinoma. Mol Cancer (2012) 11:14. doi: 10.1186/1476-4598-11-14

79. Kim RD, Sarker D, Meyer T, Yau T, Macarulla T, Park JW, et al. First-InHuman Phase I Study of Fisogatinib (BLU-554) Validates Aberrant FGF19 Signaling as a Driver Event in Hepatocellular Carcinoma. Cancer Discov (2019) 9:1696-707. doi: 10.1158/2159-8290.Cd-19-0555

80. Hua H, Kong Q, Yin J, Zhang J, Jiang Y. Insulin-Like Growth Factor Receptor Signaling in Tumorigenesis and Drug Resistance: A Challenge for Cancer Therapy. J Hematol Oncol (2020) 13:64. doi: 10.1186/s13045-02000904-3

81. Iams WT, Lovly CM. Molecular Pathways: Clinical Applications and Future Direction of Insulin-Like Growth Factor-1 Receptor Pathway Blockade. Clin Cancer Res (2015) 21:4270-7. doi: 10.1158/1078-0432.Ccr-14-2518

82. Tovar V, Alsinet C, Villanueva A, Hoshida Y, Chiang DY, Solé M, et al. IGF Activation in a Molecular Subclass of Hepatocellular Carcinoma and PreClinical Efficacy of IGF-1R Blockage. J Hepatol (2010) 52:550-9. doi: 10.1016/j.jhep.2010.01.015

83. Qu X, Wu Z, Dong W, Zhang T, Wang L, Pang Z, et al. Update of IGF-1 Receptor Inhibitor (Ganitumab, Dalotuzumab, Cixutumumab, Teprotumumab and Figitumumab) Effects on Cancer Therapy. Oncotarget (2017) 8:29501-18. doi: 10.18632/oncotarget.15704

84. Abou-Alfa GK, Capanu M, O'Reilly EM, Ma J, Chou JF, Gansukh B, et al. A Phase II Study of Cixutumumab (IMC-A12, NSC742460) in Advanced Hepatocellular Carcinoma. J Hepatol (2014) 60:319-24. doi: 10.1016/ j.jhep.2013.09.008

85. Zhang YC, Wang XP, Zhang LY, Song AL, Kou ZM, Li XS. Effect of Blocking IGF-I Receptor on Growth of Human Hepatocellular Carcinoma Cells. World J Gastroenterol (2006) 12:3977-82. doi: 10.3748/wjg.v12.i25.3977

86. El-Khoueiry AB, O'Donnell R, Semrad TJ, Mack P, Blanchard S, Bahary N, et al. A Phase I Trial of Escalating Doses of Cixutumumab (IMC-A12) and Sorafenib in the Treatment of Advanced Hepatocellular Carcinoma. Cancer Chemother Pharmacol (2018) 81:957-63. doi: 10.1007/s00280-018-3553-4

87. George B, George SK, Shi W, Haque A, Shi P, Eskandari G, et al. Dual Inhibition of IGF-IR and ALK as an Effective Strategy to Eradicate NPMALK(+) T-Cell Lymphoma. J Hematol Oncol (2019) 12:80. doi: 10.1186/ s13045-019-0768-8

88. Lee JS, Kang JH, Boo HJ, Hwang SJ, Hong S, Lee SC, et al. STAT3-Mediated IGF-2 Secretion in the Tumour Microenvironment Elicits Innate Resistance to Anti-IGF-1R Antibody. Nat Commun (2015) 6:8499. doi: 10.1038/ ncomms 9499

89. Bouattour M, Raymond E, Qin S, Cheng AL, Stammberger U, Locatelli G, et al. Recent Developments of C-Met as a Therapeutic Target in Hepatocellular Carcinoma. Hepatology (2018) 67:1132-49. doi: 10.1002/ hep. 29496

90. Garajová I, Giovannetti E, Biasco G, Peters GJ. C-Met as a Target for Personalized Therapy. Transl Oncogenom (2015) 7:13-31. doi: 10.4137/ tog.S30534

91. Bladt F, Friese-Hamim M, Ihling C, Wilm C, Blaukat A. The C-Met Inhibitor MSC2156119J Effectively Inhibits Tumor Growth in Liver Cancer Models. Cancers (Basel) (2014) 6:1736-52. doi: 10.3390/ cancers6031736

92. Santoro A, Simonelli M, Rodriguez-Lope C, Zucali P, Camacho LH, Granito A, et al. A Phase-1b Study of Tivantinib (ARQ 197) in Adult Patients With Hepatocellular Carcinoma and Cirrhosis. Br J Cancer (2013) 108:21-4. doi: 10.1038/bjc.2012.556

93. Santoro A, Rimassa L, Borbath I, Daniele B, Salvagni S, Van Laethem JL, et al. Tivantinib for Second-Line Treatment of Advanced Hepatocellular Carcinoma: A Randomised, Placebo-Controlled Phase 2 Study. Lancet Oncol (2013) 14:55-63. doi: 10.1016/s1470-2045(12)70490-4

94. Rimassa L, Assenat E, Peck-Radosavljevic M, Pracht M, Zagonel V, Mathurin P, et al. Tivantinib for Second-Line Treatment of MET-High, Advanced Hepatocellular Carcinoma (METIV-HCC): A Final Analysis of a Phase 3, Randomised, Placebo-Controlled Study. Lancet Oncol (2018) 19:682-93. doi: 10.1016/s1470-2045(18)30146-3

95. Kudo M, Morimoto M, Moriguchi M, Izumi N, Takayama T, Yoshiji H, et al. A Randomized, Double-Blind, Placebo-Controlled, Phase 3 Study of
Tivantinib in Japanese Patients With MET-High Hepatocellular Carcinoma. Cancer Sci (2020) 111:3759-69. doi: 10.1111/cas.14582

96. Decaens T, Barone C, Assenat E, Wermke M, Fasolo A, Merle P, et al. Phase 1b/2 Trial of Tepotinib in Sorafenibpretreated Advanced Hepatocellular Carcinoma With MET Overexpression. Br J Cancer (2021) 1-10. doi: 10.1038/s41416-021-01334-9

97. Sulpice E, Ding S, Muscatelli-Groux B, Bergé M, Han ZC, Plouet J, et al. Cross-Talk Between the VEGF-A and HGF Signalling Pathways in Endothelial Cells. Biol Cell (2009) 101:525-39. doi: 10.1042/bc20080221

98. Harding JJ, Zhu AX, Bauer TM, Choueiri TK, Drilon A, Voss MH, et al. A Phase Ib/II Study of Ramucirumab in Combination With Emibetuzumab in Patients With Advanced Cancer. Clin Cancer Res (2019) 25:5202-11. doi: 10.1158/1078-0432.Ccr-18-4010

99. Qin S, Chan SL, Sukeepaisarnjaroen W, Han G, Choo SP, Sriuranpong V, et al. A Phase II Study of the Efficacy and Safety of the MET Inhibitor Capmatinib (INC280) in Patients With Advanced Hepatocellular Carcinoma. Ther Adv Med Oncol (2019) 11:1758835919889001. doi: $10.1177 / 1758835919889001$

100. Yau TCC, Lencioni R, Sukeepaisarnjaroen W, Chao Y, Yen CJ, Lausoontornsiri W, et al. A Phase I/II Multicenter Study of Single-Agent Foretinib as First-Line Therapy in Patients With Advanced Hepatocellular Carcinoma. Clin Cancer Res (2017) 23:2405-13. doi: 10.1158/10780432.Ccr-16-1789

101. Fagiani E, Christofori G. Angiopoietins in Angiogenesis. Cancer Lett (2013) 328:18-26. doi: 10.1016/j.canlet.2012.08.018

102. Oliner J, Min H, Leal J, Yu D, Rao S, You E, et al. Suppression of Angiogenesis and Tumor Growth by Selective Inhibition of Angiopoietin2. Cancer Cell (2004) 6:507-16. doi: 10.1016/j.ccr.2004.09.030

103. Abou-Alfa GK, Blanc JF, Miles S, Ganten T, Trojan J, Cebon J, et al. Phase II Study of First-Line Trebananib Plus Sorafenib in Patients With Advanced Hepatocellular Carcinoma. Oncologist (2017) 22:780-e765. doi: 10.1634/ theoncologist.2017-0058

104. Hao Y, Baker D, Ten Dijke P. TGF- $\beta$-Mediated Epithelial-Mesenchymal Transition and Cancer Metastasis. Int J Mol Sci (2019) 20:2767. doi: 10.3390/ ijms20112767

105. Yi M, Zhang J, Li A, Niu M, Yan Y, Jiao Y, et al. The Construction, Expression, and Enhanced Anti-Tumor Activity of YM101: A Bispecific Antibody Simultaneously Targeting TGF- $\beta$ and PD-L1. J Hematol Oncol (2021) 14:27. doi: 10.1186/s13045-021-01045-x

106. Bai X, Yi M, Jiao Y, Chu Q, Wu K. Blocking TGF- $\beta$ Signaling to Enhance the Efficacy of Immune Checkpoint Inhibitor. Oncol Targets Ther (2019) 12:9527-38. doi: 10.2147/ott.S224013

107. Faivre S, Santoro A, Kelley RK, Gane E, Costentin CE, Gueorguieva I, et al. Novel Transforming Growth Factor Beta Receptor I Kinase Inhibitor Galunisertib (LY2157299) in Advanced Hepatocellular Carcinoma. Liver Int (2019) 39:1468-77. doi: 10.1111/liv.14113

108. Ungerleider N, Han C, Zhang J, Yao L, Wu T. Tgf $\beta$ Signaling Confers Sorafenib Resistance via Induction of Multiple RTKs in Hepatocellular Carcinoma Cells. Mol Carcinog (2017) 56:1302-11. doi: 10.1002/mc.22592

109. Yin Y, Hua H, Li M, Liu S, Kong Q, Shao T, et al. mTORC2 Promotes Type I Insulin-Like Growth Factor Receptor and Insulin Receptor Activation Through the Tyrosine Kinase Activity of mTOR. Cell Res (2016) 26:46-65. doi: 10.1038/cr.2015.133

110. Lu X, Paliogiannis P, Calvisi DF, Chen X. Role of the Mammalian Target of Rapamycin Pathway in Liver Cancer: From Molecular Genetics to Targeted Therapies. Hepatology (2021) 73(Suppl 1):49-61. doi: 10.1002/hep.31310

111. Hagiwara A, Cornu M, Cybulski N, Polak P, Betz C, Trapani F, et al. Hepatic Mtorc2 Activates Glycolysis and Lipogenesis Through Akt, Glucokinase, and SREBP1c. Cell Metab (2012) 15:725-38. doi: 10.1016/j.cmet.2012.03.015

112. Hua H, Kong Q, Zhang H, Wang J, Luo T, Jiang Y. Targeting mTOR for Cancer Therapy. J Hematol Oncol (2019) 12:71. doi: 10.1186/s13045-0190754-1

113. Hui IC, Tung EK, Sze KM, Ching YP, Ng IO. Rapamycin and CCI-779 Inhibit the Mammalian Target of Rapamycin Signalling in Hepatocellular Carcinoma. Liver Int (2010) 30:65-75. doi: 10.1111/j.1478-3231. 2009.02117.x

114. Huynh H, Chow KH, Soo KC, Toh HC, Choo SP, Foo KF, et al. RAD001 (Everolimus) Inhibits Tumour Growth in Xenograft Models of Human 
Hepatocellular Carcinoma. J Cell Mol Med (2009) 13:1371-80. doi: 10.1111/ j.1582-4934.2008.00364.x

115. Xie Z, Wang J, Liu M, Chen D, Qiu C, Sun K. CC-223 Blocks Mtorc1/C2 Activation and Inhibits Human Hepatocellular Carcinoma Cells In Vitro and In Vivo. PloS One (2017) 12:e0173252. doi: 10.1371/journal.pone.0173252

116. Shiah HS, Chen CY, Dai CY, Hsiao CF, Lin YJ, Su WC, et al. Randomised Clinical Trial: Comparison of Two Everolimus Dosing Schedules in Patients With Advanced Hepatocellular Carcinoma. Aliment Pharmacol Ther (2013) 37:62-73. doi: 10.1111/apt.12132

117. Zhu AX, Kudo M, Assenat E, Cattan S, Kang YK, Lim HY, et al. Effect of Everolimus on Survival in Advanced Hepatocellular Carcinoma After Failure of Sorafenib: The EVOLVE-1 Randomized Clinical Trial. JAMA (2014) 312:57-67. doi: 10.1001/jama.2014.7189

118. Schnitzbauer AA, Filmann N, Adam R, Bachellier P, Bechstein WO, Becker T, et al. mTOR Inhibition Is Most Beneficial After Liver Transplantation for Hepatocellular Carcinoma in Patients With Active Tumors. Ann Surg (2020) 272:855-62. doi: 10.1097/sla.0000000000004280

119. Knox JJ, Qin R, Strosberg JR, Tan B, Kaubisch A, El-Khoueiry AB, et al. A Phase II Trial of Bevacizumab Plus Temsirolimus in Patients With Advanced Hepatocellular Carcinoma. Invest New Drugs (2015) 33:241-6. doi: 10.1007/ s10637-014-0169-3

120. Koeberle D, Dufour JF, Demeter G, Li Q, Ribi K, Samaras P, et al. Sorafenib With or Without Everolimus in Patients With Advanced Hepatocellular Carcinoma (HCC): A Randomized Multicenter, Multinational Phase II Trial (SAKK 77/08 and SASL 29). Ann Oncol (2016) 27:856-61. doi: 10.1093/ annonc/mdw054

121. Liu X, Hu J, Song X, Utpatel K, Zhang Y, Wang P, et al. Combined Treatment With MEK and mTOR Inhibitors Is Effective in In Vitro and In Vivo Models of Hepatocellular Carcinoma. Cancers (Basel) (2019) 11:930. doi: 10.3390/ cancers 11070930

122. Liu AM, Xu Z, Luk JM. An Update on Targeting Hippo-YAP Signaling in Liver Cancer. Expert Opin Ther Targ (2012) 16:243-7. doi: 10.1517/ 14728222.2012 .662958

123. Dai XY, Zhuang LH, Wang DD, Zhou TY, Chang LL, Gai RH, et al. Nuclear Translocation and Activation of YAP by Hypoxia Contributes to the Chemoresistance of SN38 in Hepatocellular Carcinoma Cells. Oncotarget (2016) 7:6933-47. doi: 10.18632/oncotarget.6903

124. Zhu H, Wang DD, Yuan T, Yan FJ, Zeng CM, Dai XY, et al. Multikinase Inhibitor CT-707 Targets Liver Cancer by Interrupting the HypoxiaActivated IGF-1r-YAP Axis. Cancer Res (2018) 78:3995-4006. doi: 10.1158/0008-5472.Can-17-1548

125. Schmidt CM, McKillop IH, Cahill PA, Sitzmann JV. Increased MAPK Expression and Activity in Primary Human Hepatocellular Carcinoma. Biochem Biophys Res Commun (1997) 236:54-8. doi: 10.1006/bbrc.1997.6840

126. Calvisi DF, Ladu S, Gorden A, Farina M, Conner EA, Lee JS, et al. Ubiquitous Activation of Ras and Jak/Stat Pathways in Human HCC. Gastroenterology (2006) 130:1117-28. doi: 10.1053/j.gastro.2006.01.006

127. O'Neil BH, Goff LW, Kauh JS, Strosberg JR, Bekaii-Saab TS, Lee RM, et al. Phase II Study of the Mitogen-Activated Protein Kinase 1/2 Inhibitor Selumetinib in Patients With Advanced Hepatocellular Carcinoma. J Clin Oncol (2011) 29:2350-6. doi: 10.1200/jco.2010.33.9432

128. Davies BR, Logie A, McKay JS, Martin P, Steele S, Jenkins R, et al. AZD6244 (ARRY-142886), a Potent Inhibitor of Mitogen-Activated Protein Kinase/ Extracellular Signal-Regulated Kinase Kinase 1/2 Kinases: Mechanism of Action In Vivo, Pharmacokinetic/Pharmacodynamic Relationship, and Potential for Combination in Preclinical Models. Mol Cancer Ther (2007) 6:2209-19. doi: 10.1158/1535-7163.Mct-07-0231

129. Tai WM, Yong WP, Lim C, Low LS, Tham CK, Koh TS, et al. A Phase Ib Study of Selumetinib (AZD6244, ARRY-142886) in Combination With Sorafenib in Advanced Hepatocellular Carcinoma (HCC). Ann Oncol (2016) 27:2210-5. doi: 10.1093/annonc/mdw415

130. Lim HY, Heo J, Choi HJ, Lin CY, Yoon JH, Hsu C, et al. A Phase II Study of the Efficacy and Safety of the Combination Therapy of the MEK Inhibitor Refametinib (BAY 86-9766) Plus Sorafenib for Asian Patients With Unresectable Hepatocellular Carcinoma. Clin Cancer Res (2014) 20:597685. doi: 10.1158/1078-0432.Ccr-13-3445

131. Lim HY, Merle P, Weiss KH, Yau T, Ross P, Mazzaferro V, et al. Phase II Studies With Refametinib or Refametinib Plus Sorafenib in Patients With
RAS-Mutated Hepatocellular Carcinoma. Clin Cancer Res (2018) 24:465061. doi: 10.1158/1078-0432.Ccr-17-3588

132. Al Zaid Siddiquee K, Turkson J. STAT3 as a Target for Inducing Apoptosis in Solid and Hematological Tumors. Cell Res (2008) 18:254-67. doi: 10.1038/ cr.2008.18

133. He G, Yu GY, Temkin V, Ogata H, Kuntzen C, Sakurai T, et al. Hepatocyte IKKbeta/NF-kappaB Inhibits Tumor Promotion and Progression by Preventing Oxidative Stress-Driven STAT3 Activation. Cancer Cell (2010) 17:286-97. doi: 10.1016/j.ccr.2009.12.048

134. Takeda K, Akira S. STAT Family of Transcription Factors in CytokineMediated Biological Responses. Cytokine Growth Factor Rev (2000) 11:199207. doi: 10.1016/s1359-6101(00)00005-8

135. Wan S, Zhao E, Kryczek I, Vatan L, Sadovskaya A, Ludema G, et al. Tumor-Associated Macrophages Produce Interleukin 6 and Signal via STAT3 to Promote Expansion of Human Hepatocellular Carcinoma Stem Cells. Gastroenterology (2014) 147:1393-404. doi: 10.1053/j.gastro. 2014.08.039

136. Yin X, Zhang BH, Zheng SS, Gao DM, Qiu SJ, Wu WZ, et al. Coexpression of Gene Oct4 and Nanog Initiates Stem Cell Characteristics in Hepatocellular Carcinoma and Promotes Epithelial-Mesenchymal Transition Through Activation of Stat3/Snail Signaling. J Hematol Oncol (2015) 8:23. doi: 10.1186/s13045-015-0119-3

137. Lin L, Amin R, Gallicano GI, Glasgow E, Jogunoori W, Jessup JM, et al. The STAT3 Inhibitor NSC 74859 Is Effective in Hepatocellular Cancers With Disrupted TGF-Beta Signaling. Oncogene (2009) 28:961-72. doi: 10.1038/ onc.2008.448

138. Yoo C, Kang J, Lim HY, Kim JH, Lee MA, Lee KH, et al. Phase I DoseFinding Study of OPB-111077, a Novel STAT3 Inhibitor, in Patients With Advanced Hepatocellular Carcinoma. Cancer Res Treat (2019) 51:510-8. doi: 10.4143/crt.2018.226

139. Christian S, Winkler R, Helfrich I, Boos AM, Besemfelder E, Schadendorf D, et al. Endosialin (Tem1) Is a Marker of Tumor-Associated Myofibroblasts and Tumor Vessel-Associated Mural Cells. Am J Pathol (2008) 172:486-94. doi: 10.2353/ajpath.2008.070623

140. Tomkowicz B, Rybinski K, Foley B, Ebel W, Kline B, Routhier E, et al. Interaction of Endosialin/TEM1 With Extracellular Matrix Proteins Mediates Cell Adhesion and Migration. Proc Natl Acad Sci USA (2007) 104:17965-70. doi: 10.1073/pnas.0705647104

141. Diaz LAJr., Coughlin CM, Weil SC, Fishel J, Gounder MM, Lawrence S, et al. A First-in-Human Phase I Study of MORAb-004, A Monoclonal Antibody to Endosialin in Patients With Advanced Solid Tumors. Clin Cancer Res (2015) 21:1281-8. doi: 10.1158/1078-0432.Ccr-14-1829

142. Doi T, Aramaki T, Yasui H, Muro K, Ikeda M, Okusaka T, et al. A Phase I Study of Ontuxizumab, a Humanized Monoclonal Antibody Targeting Endosialin, in Japanese Patients With Solid Tumors. Invest New Drugs (2019) 37:1061-74. doi: 10.1007/s10637-018-0713-7

143. Ollauri-Ibáñez C, Ayuso-Íñigo B, Pericacho M. Hot and Cold Tumors: Is Endoglin (CD105) a Potential Target for Vessel Normalization? Cancers (Basel) (2021) 13:1552. doi: 10.3390/cancers13071552

144. Nolan-Stevaux O, Zhong W, Culp S, Shaffer K, Hoover J, Wickramasinghe D, et al. Endoglin Requirement for BMP9 Signaling in Endothelial Cells Reveals New Mechanism of Action for Selective Anti-Endoglin Antibodies. PloS One (2012) 7:e50920. doi: 10.1371/journal.pone.0050920

145. Duffy AG, Ulahannan SV, Cao L, Rahma OE, Makarova-Rusher OV, Kleiner DE, et al. A Phase II Study of TRC105 in Patients With Hepatocellular Carcinoma Who Have Progressed on Sorafenib. United Eur Gastroenterol J (2015) 3:453-61. doi: 10.1177/2050640615583587

146. Duffy AG, Ma C, Ulahannan SV, Rahma OE, Makarova-Rusher O, Cao L, et al. Phase I and Preliminary Phase II Study of TRC105 in Combination With Sorafenib in Hepatocellular Carcinoma. Clin Cancer Res (2017) 23:4633-41. doi: 10.1158/1078-0432.Ccr-16-3171

147. Asghar U, Witkiewicz AK, Turner NC, Knudsen ES. The History and Future of Targeting Cyclin-Dependent Kinases in Cancer Therapy. Nat Rev Drug Discov (2015) 14:130-46. doi: 10.1038/nrd4504

148. Li T, Zhang C, Hassan S, Liu X, Song F, Chen K, et al. Histone Deacetylase 6 in Cancer. J Hematol Oncol (2018) 11:111. doi: 10.1186/s13045-018-0654-9

149. Khatib ZA, Matsushime H, Valentine M, Shapiro DN, Sherr CJ, Look AT. Coamplification of the CDK4 Gene With MDM2 and GLI in Human 
Sarcomas. Cancer Res (1993) 53:5535-41. doi: 10.1002/1097-0142(19931115) 72:10<3131::AID-CNCR2820721039>3.0.CO

150. Park S, Lee J, Do IG, Jang J, Rho K, Ahn S, et al. Aberrant CDK4 Amplification in Refractory Rhabdomyosarcoma as Identified by Genomic Profiling. Sci Rep (2014) 4:3623. doi: 10.1038/srep03623

151. Xu H, Yu S, Liu Q, Yuan X, Mani S, Pestell RG, et al. Recent Advances of Highly Selective CDK4/6 Inhibitors in Breast Cancer. J Hematol Oncol (2017) 10:97. doi: 10.1186/s13045-017-0467-2

152. Bollard J, Miguela V, Ruiz de Galarreta M, Venkatesh A, Bian CB, Roberto MP, et al. Palbociclib (PD-0332991), A Selective CDK4/6 Inhibitor, Restricts Tumour Growth in Preclinical Models of Hepatocellular Carcinoma. Gut (2017) 66:1286-96. doi: 10.1136/gutjnl-2016-312268

153. Reiter FP, Denk G, Ziesch A, Ofner A, Wimmer R, Hohenester S, et al. Predictors of Ribociclib-Mediated Antitumour Effects in Native and Sorafenib-Resistant Human Hepatocellular Carcinoma Cells. Cell Oncol (Dordr) (2019) 42:705-15. doi: 10.1007/s13402-019-00458-8

154. Li Y, Seto E. HDACs and HDAC Inhibitors in Cancer Development and Therapy. Cold Spring Harb Perspect Med (2016) 6:a026831. doi: 10.1101/ cshperspect.a026831

155. Bitzer M, Horger M, Giannini EG, Ganten TM, Wörns MA, Siveke JT, et al. Resminostat Plus Sorafenib as Second-Line Therapy of Advanced Hepatocellular Carcinoma-The SHELTER Study. J Hepatol (2016) 65:2808. doi: 10.1016/j.jhep.2016.02.043

156. Tak WY, Ryoo BY, Lim HY, Kim DY, Okusaka T, Ikeda M, et al. Phase I/II Study of First-Line Combination Therapy With Sorafenib Plus Resminostat, an Oral HDAC Inhibitor, Versus Sorafenib Monotherapy for Advanced Hepatocellular Carcinoma in East Asian Patients. Invest New Drugs (2018) 36:1072-84. doi: 10.1007/s10637-018-0658-x

157. Zhang L, Ding J, Li HY, Wang ZH, Wu J. Immunotherapy for Advanced Hepatocellular Carcinoma, Where Are We? Biochim Biophys Acta Rev Cancer (2020) 1874:188441. doi: 10.1016/j.bbcan.2020.188441

158. Yi M, Niu M, Xu L, Luo S, Wu K. Regulation of PD-L1 Expression in the Tumor Microenvironment. J Hematol Oncol (2021) 14:10. doi: 10.1186/ s13045-020-01027-5

159. Niu M, Yi M, Li N, Luo S, Wu K. Predictive Biomarkers of Anti-PD-1/PD-L1 Therapy in NSCLC. Exp Hematol Oncol (2021) 10:18. doi: 10.1186/s40164021-00211-8

160. Qin S, Xu L, Yi M, Yu S, Wu K, Luo S. Novel Immune Checkpoint Targets: Moving Beyond PD-1 and CTLA-4. Mol Cancer (2019) 18:155. doi: 10.1186/ s12943-019-1091-2

161. Qin S, Dong B, Yi M, Chu Q, Wu K. Prognostic Values of TIM-3 Expression in Patients With Solid Tumors: A Meta-Analysis and Database Evaluation. Front Oncol (2020) 10:1288. doi: 10.3389/fonc.2020.01288

162. Wu K, Yi M, Qin S, Chu Q, Zheng X, Wu K. The Efficacy and Safety of Combination of PD-1 and CTLA-4 Inhibitors: A Meta-Analysis. Exp Hematol Oncol (2019) 8:26. doi: 10.1186/s40164-019-0150-0

163. Duerinck J, Schwarze JK, Awada G, Tijtgat J, Vaeyens F, Bertels C, et al. Intracerebral Administration of CTLA-4 and PD-1 Immune Checkpoint Blocking Monoclonal Antibodies in Patients With Recurrent Glioblastoma: A Phase I Clinical Trial. J Immunother Cancer (2021) 9:e002296. doi: 10.1136/jitc-2020-002296

164. Yi M, Jiao D, Xu H, Liu Q, Zhao W, Han X, et al. Biomarkers for Predicting Efficacy of PD-1/PD-L1 Inhibitors. Mol Cancer (2018) 17:129. doi: 10.1186/ s12943-018-0864-3

165. Chen Y, Wang Y, Luo H, Meng X, Zhu W, Wang D, et al. The Frequency and Inter-Relationship of PD-L1 Expression and Tumour Mutational Burden Across Multiple Types of Advanced Solid Tumours in China. Exp Hematol Oncol (2020) 9:17. doi: 10.1186/s40164-020-00173-3

166. Yau T, Kang YK, Kim TY, El-Khoueiry AB, Santoro A, Sangro B, et al. Efficacy and Safety of Nivolumab Plus Ipilimumab in Patients With Advanced Hepatocellular Carcinoma Previously Treated With Sorafenib: The CheckMate 040 Randomized Clinical Trial. JAMA Oncol (2020) 6: e204564. doi: 10.1001/jamaoncol.2020.4564

167. El-Khoueiry AB, Sangro B, Yau T, Crocenzi TS, Kudo M, Hsu C, et al. Nivolumab in Patients With Advanced Hepatocellular Carcinoma (CheckMate 040): An Open-Label, Non-Comparative, Phase 1/2 Dose Escalation and Expansion Trial. Lancet (2017) 389:2492-502. doi: 10.1016/ s0140-6736(17)31046-2
168. Zhu AX, Finn RS, Edeline J, Cattan S, Ogasawara S, Palmer D, et al. Pembrolizumab in Patients With Advanced Hepatocellular Carcinoma Previously Treated With Sorafenib (KEYNOTE-224): A Non-Randomised, Open-Label Phase 2 Trial. Lancet Oncol (2018) 19:940-52. doi: 10.1016/ s1470-2045(18)30351-6

169. Luo XY, Wu KM, He XX. Advances in Drug Development for Hepatocellular Carcinoma: Clinical Trials and Potential Therapeutic Targets. J Exp Clin Cancer Res (2021) 40:172. doi: 10.1186/s13046-021-01968-w

170. Yi M, Jiao D, Qin S, Chu Q, Wu K, Li A. Synergistic Effect of Immune Checkpoint Blockade and Anti-Angiogenesis in Cancer Treatment. Mol Cancer (2019) 18:60. doi: 10.1186/s12943-019-0974-6

171. Herbst RS, Soria JC, Kowanetz M, Fine GD, Hamid O, Gordon MS, et al. Predictive Correlates of Response to the Anti-PD-L1 Antibody MPDL3280A in Cancer Patients. Nature (2014) 515:563-7. doi: 10.1038/nature14011

172. Siegel AB, Cohen EI, Ocean A, Lehrer D, Goldenberg A, Knox JJ, et al. Phase II Trial Evaluating the Clinical and Biologic Effects of Bevacizumab in Unresectable Hepatocellular Carcinoma. J Clin Oncol (2008) 26:2992-8. doi: 10.1200/jco.2007.15.9947

173. Lee MS, Ryoo BY, Hsu CH, Numata K, Stein S, Verret W, et al. Atezolizumab With or Without Bevacizumab in Unresectable Hepatocellular Carcinoma (GO30140): An Open-Label, Multicentre, Phase 1b Study. Lancet Oncol (2020) 21:808-20. doi: 10.1016/s1470-2045(20)30156-x

174. Finn RS, Ikeda M, Zhu AX, Sung MW, Baron AD, Kudo M, et al. Phase Ib Study of Lenvatinib Plus Pembrolizumab in Patients With Unresectable Hepatocellular Carcinoma. J Clin Oncol (2020) 38:2960-70. doi: 10.1200/ jco. 20.00808

175. Bang YJ, Golan T, Dahan L, Fu S, Moreno V, Park K, et al. Ramucirumab and Durvalumab for Previously Treated, Advanced Non-Small-Cell Lung Cancer, Gastric/Gastro-Oesophageal Junction Adenocarcinoma, or Hepatocellular Carcinoma: An Open-Label, Phase Ia/b Study (JVDJ). Eur J Cancer (2020) 137:272-84. doi: 10.1016/j.ejca.2020.06.007

176. Xu J, Zhang Y, Jia R, Yue C, Chang L, Liu R, et al. Anti-PD-1 Antibody SHR1210 Combined With Apatinib for Advanced Hepatocellular Carcinoma, Gastric, or Esophagogastric Junction Cancer: An Open-Label, Dose Escalation and Expansion Study. Clin Cancer Res (2019) 25:515-23. doi: 10.1158/1078-0432.Ccr-18-2484

177. Lin H, Ma J, Zhuo M, Zhang C, Luo J, Zhuang X, et al. Preliminary Results of the Phase II ALTER-H003 Trial: Anlotinib Plus Toripalimab as a FirstLine Treatment for Patients With Unresectable Hepatocellular Carcinoma. J Clin Oncol (2021) 39:314. doi: 10.1200/JCO.2021. 39.3_suppl.314

178. Chen X, Li W, Wu X, Zhao F, Wu H, Gu Y, et al. 170p Sintilimab Plus Anlotinib as First-Line Therapy in Patients (Pts) With Advanced Hepatocellular Carcinoma (aHCC). Ann Oncol (2020) 31:S1305. doi: 10.1016/j.annonc.2020.10.191

179. Li A, Yi M, Qin S, Chu Q, Luo S, Wu K. Prospects for Combining Immune Checkpoint Blockade With PARP Inhibition. J Hematol Oncol (2019) 12:98. doi: 10.1186/s13045-019-0784-8

180. Tomás-Loba A, Manieri E, González-Terán B, Mora A, Leiva-Vega L, Santamans AM, et al. P38y Is Essential for Cell Cycle Progression and Liver Tumorigenesis. Nature (2019) 568:557-60. doi: 10.1038/s41586-019$1112-8$

181. Ren M, Xu H, Xia H, Tang Q, Bi F. Simultaneously Targeting SOAT1 and CPT1A Ameliorates Hepatocellular Carcinoma by Disrupting Lipid Homeostasis. Cell Death Discov (2021) 7:125. doi: 10.1038/s41420-02100504-1

182. Liu F, Qin L, Liao Z, Song J, Yuan C, Liu Y, et al. Microenvironment Characterization and Multi-Omics Signatures Related to Prognosis and Immunotherapy Response of Hepatocellular Carcinoma. Exp Hematol Oncol (2020) 9:10. doi: 10.1186/s40164-020-00165-3

183. Chen T, Dai X, Dai J, Ding C, Zhang Z, Lin Z, et al. AFP Promotes HCC Progression by Suppressing the HuR-Mediated Fas/FADD Apoptotic Pathway. Cell Death Dis (2020) 11:822. doi: 10.1038/s41419-02003030-7

184. Lai SC, Su YT, Chi CC, Kuo YC, Lee KF, Wu YC, et al. DNMT3b/OCT4 Expression Confers Sorafenib Resistance and Poor Prognosis of Hepatocellular Carcinoma Through IL-6/STAT3 Regulation. J Exp Clin Cancer Res (2019) 38:474. doi: 10.1186/s13046-019-1442-2 
185. Tan W, Luo X, Li W, Zhong J, Cao J, Zhu S, et al. TNF- $\alpha$ Is a Potential Therapeutic Target to Overcome Sorafenib Resistance in Hepatocellular Carcinoma. EBioMedicine (2019) 40:446-56. doi: 10.1016/j.ebiom. 2018.12.047

Conflict of Interest: The authors declare that the research was conducted in the absence of any commercial or financial relationships that could be construed as a potential conflict of interest.

Publisher's Note: All claims expressed in this article are solely those of the authors and do not necessarily represent those of their affiliated organizations, or those of the publisher, the editors and the reviewers. Any product that may be evaluated in this article, or claim that may be made by its manufacturer, is not guaranteed or endorsed by the publisher.

Copyright $\odot 2021 \mathrm{Niu}, \mathrm{Yi}, \mathrm{Li}, \mathrm{Wu}$ and $\mathrm{Wu}$. This is an open-access article distributed under the terms of the Creative Commons Attribution License (CC BY). The use, distribution or reproduction in other forums is permitted, provided the original author(s) and the copyright owner(s) are credited and that the original publication in this journal is cited, in accordance with accepted academic practice. No use, distribution or reproduction is permitted which does not comply with these terms. 